\title{
Detection of Single Nucleotide Polymorphisms
}

\author{
Pui-Yan Kwok $^{1 *}$ and Xiangning Chen ${ }^{2}$ \\ ${ }^{1}$ Cardiovascular Research Institute, University of California, \\ 505 Parnassus Avenue, Long 1332A, Box 0130, San \\ Francisco, CA 94143-0130, USA \\ ${ }^{2}$ Virginia Institute for Psychiatric and Behavioral Genetics, \\ Virginia Commonwealth University, 800 E. Leigh Street, \\ Suite 1-101, Richmond, VA 23298-0424, USA
}

\begin{abstract}
Single nucleotide polymorphism (SNP) detection technologies are used to scan for new polymorphisms and to determine the allele(s) of a known polymorphism in target sequences. SNP detection technologies have evolved from labor intensive, time consuming, and expensive processes to some of the most highly automated, efficient, and relatively inexpensive methods. Driven by the Human Genome Project, these technologies are now maturing and robust strategies are found in both SNP discovery and genotyping areas. The nearly completed human genome sequence provides the reference against which all other sequencing data can be compared. Global SNP discovery is therefore only limited by the amount of funding available for the activity. Local, target, SNP discovery relies mostly on direct DNA sequencing or on denaturing high performance liquid chromatography (dHPLC). The number of SNP genotyping methods has exploded in recent years and many robust methods are currently available. The demand for SNP genotyping is great, however, and no one method is able to meet the needs of all studies using SNPs. Despite the considerable gains over the last decade, new approaches must be developed to lower the cost and increase the speed of SNP detection.
\end{abstract}

\section{Introduction}

When any two human genomes are compared side by side, they are $99.9 \%$ identical (Cooper et al., 1985). However, with a 3.2 billion base pair genome, each person harbors some 3.2 million differences in his/her diploid genome. Most of the differences are due to single base substitution polymorphisms, popularly known as single nucleotide polymorphisms (SNPs). While the majority of the SNPs are of no biological consequence, a fraction of the substitutions have functional significance and are the basis for the diversity found among humans (Collins et al., 1997). As genetic markers, SNPs can be used to follow the inheritance patterns of chromosomal regions from generation to generation and are powerful tools in the study of genetic factors associated with human diseases (Johnson and Todd, 2000; Risch, 2000). The study of DNA

*For correspondence. Email kwok@cvrimail.ucsf.edu. sequence variation became feasible when enzymatic and chemical methods of DNA manipulation were discovered. As the demand for genetic analysis increases, SNP detection technologies are developed at an accelerated pace, fueled by recent advances in enzymology, DNA synthesis, and analytical instrumentation.

SNP detection encompasses two broad areas: scanning DNA sequences for previously unknown polymorphisms and screening (genotyping) individuals for known polymorphisms. Scanning for new SNPs can be further divided into the global, or random, approach and the regional, or targeted, approach. Although the technologies capable of scanning DNA for new polymorphisms can be used in screening individuals for known polymorphisms, there are many more options for SNP genotyping. Indeed, many of the most exciting genome technologies are those developed for genotyping tens of thousands of SNPs in thousands of individuals. Furthermore, SNP detection technologies are applicable not only to humans, but to any living organism on earth.

The evolution of SNP detection technology is characterized by the clever adoption of new biological methods, fluorescent and other reporters, computational algorithms, and highly sensitive analytical instruments. Although the ideal SNP detection method does not exist, the field has come a long way from the early days and the technologies are sufficiently robust that it is now possible to conduct large-scale genetic studies. As the cost and throughput of SNP detection continue to drop, even the most ambitious studies will become economically feasible.

\section{Technologies For Global SNP Discovery}

The main issue with global SNP discovery is that on average, there is one SNP in every 1,000 bp of DNA when two human genomes are compared to each other (The International SNP Map Working Group, 2001). To maximize the chance of finding SNPs, one must be able to scan 1,000 bp pieces of DNA in a generic way. The first attempt to identify SNPs randomly in the human genome was to scan for alterations in restriction sites in the genome (Botstein et al., 1980). Although the actual sequence variation was not determined, restriction fragment length polymorphisms (RFLPs) were the first SNPs found in a random, global approach (Donis-Keller et al., 1987). Developed before the polymerase chain reaction (PCR) was even conceived, RFLP analysis was a powerful, but very laborious, strategy. High quality genomic DNA from multiple individuals were cut with a number of restriction enzymes, separated by gel electrophoresis and transferred to nylon filters. These Southern blots were then probed with random genomic clones to identify variations in the restriction fragment lengths. Because only small amounts of DNA were found on the filter, radioactive labels were used with the probes. Needless to say, this was a very labor intensive and expensive way to identify SNPS, and it was almost impossible to extract the sequence differences associated 
with the RFLPs. Furthermore, even with probes that were thousands of bases long, one was scanning only a small fraction of the bases at the restriction sites.

The situation did not improve with the advent of PCR (Saiki et al., 1985). This was due to the fact that in order for PCR to work, DNA sequence data had to be obtained to design loci-specific PCR primers. To complicate things further, DNA sequencing and oligonucleotide synthesis were both costly activities until quite recently. Global scanning of SNPs was not seriously attempted in the early 1990's because simple sequence repeat polymorphisms (SSRPs), the highly informative microsatellite markers, were much more easily developed by probing genomic libraries with synthetic oligonucleotides bearing the simple sequence repeat motifs and sequencing the positive clones (Weber and May, 1989; Litt and Luty, 1989). When physical mapping of the human genome began in earnest in the mid-1990's, many mapped sequence-tagged-sites (STSs) and their PCR primers became available (Hudson et al., 1995). Using a resequencing approach, these STSs were scanned for SNPs (Kwok et al., 1996) and several thousand SNPs were found in the first "large-scale" SNP identification project (Wang et al., 1998). However, even after all the available STSs had been scanned, the number of SNPS found amounted only to a small fraction of the SNPs needed for complex genetic analysis.

In the late 1990's, several favorable factors came together to make global SNP discovery a reality. First, the human genome project sped up its production rate in response to the efforts of a new company to sequence the human genome by whole genome shotgun sequencing. This development meant that high quality sequences of some $90 \%$ of the human genome sequence became available for comparison (International Human Genome Sequencing Consortium, 2001; Venter et al., 2001). Second, the cost and efficiency of DNA sequencing improved significantly and one can obtain millions of 500 bp sequencing reads over a relatively short time. Third, bioinformatics tools were developed to compare DNA sequences and identify, with high degree of confidence, sequence variations (Nickerson et al., 1997; Marth et al., 1999). Fourth, the SNP consortium (TSC), a coalition formed by pharmaceutical companies, high technology companies, and the British charity, Wellcome Trust, enlisted the help of 4 academic centers to identify a large number of SNPs using a modified whole genome shotgun sequencing approach (Masood, 1999; Altshuler et al., 2000).

The result of large-scale sequencing and comparing sequences deriving from different individuals (or chromosomes) at the same loci was that millions of SNPs were found in the human genome (The International SNP Map Working Group, 2001; Venter et al., 2001). The majority of the SNPs came from three sources. The first set came from analyzing overlapping large-insert clone sequences from the human genome project. When the overlapping bacterial artificial chromosome (BAC) clones came from different libraries, the overlapping sequences (most of them 20-30 kb in length) are from different individuals and many SNPs are found. Because the donors of the BAC libraries are diploid, even when the overlapping clones are from the same library, the two BACs are derived from different parental lineage $50 \%$ of the time and SNPs will be found in that situation (Taillon-Miller et al., 1998). Indeed, some 800,000 SNPs were found in the overlapping sequences by the end of year 2000 . The second set came from the TSC with data derived from the sequencing of clones from "reduced representation libraries". By reducing the complexity of the genome through cloning of sizeselected restriction fragments from a pooled DNA sample, the same loci were sequenced multiple times when a large number of clones from each library was sequenced (Altshuler et al., 2000). Even for the singleton clones, their sequences were useful for SNP discovery because they could be compared to the reference human genome sequence. Some 900,000 SNPs were deposited to the public database by the end of 2000 . The third set came from the whole genome shotgun sequencing project by a private enterprise and the data were kept from the public. This large set of SNPs is available only to "subscribers" of the private database (Venter et al., 2001). In addition to these large-scale projects, smaller efforts using a variety of approaches also contributed to the global SNP discovery project (for example, Irizzary et al., 2000; Buetow et al., 2001).

With the reference human genome sequence now close to completion, global SNP discovery is most efficient when one takes a shotgun sequencing approach and compares the sequencing data obtained against the reference sequence. The density of the markers is determined by the number of genomic clones sequenced. This approach is applicable to any organism as long as the reference sequence of that organism is available.

\section{Technologies For Targeted SNP Discovery}

Unlike global SNP discovery, where speed and achieving a certain density of marker are the most important factors, targeted SNP discovery focuses on finding most, if not all, of the SNPs in the regions of interest. Of course, DNA sequencing is the gold standard of SNP discovery and the evolution of DNA sequencing technology is described in detail in other reviews (Galas and McCormack, 2002). The breakthrough in DNA sequencing technology for SNP discovery came when direct sequencing of PCR products was perfected and the recognition that sequencing data from a heterozygote could be distinguished from those from a homozygote quite unambiguously (Kwok et al., 1994; Zakeri, 1998). However, DNA sequencing was quite labor intensive and costly until very recently and several highly successful polymorphism scanning methods were developed to scan DNA fragments for SNPs and mutations (Kwok and Chen, 1998). Most SNP scanning methods exploit the difference between the mismatched heteroduplex DNA from the perfectly matched homoduplex DNA. The earliest SNP scanning technologies distinguished the homoduplex from the heteroduplex in different ways. They were elegant methods developed without the benefit of PCR. PCR opens up other ways of looking for polymorphisms and a number of other more efficient methods have been developed for SNP discovery. 
Denaturing Gradient Gel Electrophoresis

The first method, denaturing gradient gel electrophoresis (DGGE), takes advantage of the fact that denaturation of double-stranded DNA is highly dependent on its sequence (Fischer and Lerman, 1983). In many cases, even a single nucleotide difference between two DNA molecules can change the "melting" condition enough for one to distinguish between them (Myers, et al., 1985b). Since the electrophoretic mobility of a partially-open DNA molecule is greatly retarded, a DNA fragment traversing down a gel stops at the point where one of its ends begins to melt. By the use of a gel with an increasing gradient of denaturants, it is possible to immobilize the partially melted DNA molecule at the lowest denaturant concentration that causes the molecule to open up. Therefore, DNA molecules with differences in the low melting domain will have different final positions in the gel. The mobility difference between a heteroduplex DNA molecule containing a mismatch and its homoduplex counterpart when they go down the denaturing gradient gel is even more exaggerated because the heteroduplex DNA melts at a much lower denaturant concentration and the final gel positions of the two molecules are much farther apart. By routinely mixing the test samples with a reference sample, denaturing them and letting them re-anneal before loading the mixture onto the denaturing gradient gel increases the sensitivity of the method.

Building on the sound theoretical basis of the DGGE method and with PCR, one can artificially attach a highmelting domain to the end of molecule with the highermelting domain and render the entire test fragment the "low-melting" domain. This can be in the form of a "GCclamp" or a region of crossed-linked DNA produced by UVirradiation of psoralens attached to one of the PCR primers (Sheffield et al., 1989). With these improvements, DGGE can theoretically detect all DNA variations in DNA fragments up to $1,000 \mathrm{bp}$ in size, and isolate the two separated variants from the gel for sequence analysis.

This method has been modified by replacing the chemical denaturant gradient in the gel by a temperature gradient to take advantage of the fact that a temperature gradient can be set up more reproducibly than a chemical denaturing gradient (Henco et al., 1994). Another variant uses temperature-programmed capillary electrophoresis that combines a temporal (rather than spatial) temperature gradient and the superior separation achieved by capillary electrophoresis (Gelfi et al., 1996).

\section{Chemical Cleavage of Mismatch (CCM)}

Nucleic acid chemists have observed that cytosines and thymines in single stranded DNA are oxidized more readily by hydroxylamine and osmium tetroxide, respectively, than when they are in double stranded DNA. Given this knowledge, a rational strategy for mismatch detection was developed by exposing the mixture of reannealed DNA fragments to the oxidants to modify the cytosines and thymines at the mismatched sites. The chemically modified base is then cleaved by piperidine and the point of mismatch can be ascertained by sizing the cleavage product by gel electrophoresis (Cotton et al., 1988; Cotton, 1999). Mismatched guanines and adenosines bases are identified by the use of the complementary probe, which examines their cytosine and thymine counterparts. The advantages of this method are that it detects $100 \%$ of the mismatches in relatively large DNA fragments (up to several $\mathrm{kb}$ ) and yields positional information of the polymorphic site. Its major disadvantage is the use of toxic chemicals in a multi-step reaction. However, the drawbacks of CCM can be overcome by automating some of the steps to ensure more reproducible reaction conditions and therefore more consistent results.

\section{Ribonuclease Cleavage of Mismatched DNA}

Another early SNP scanning approach is based on the observation that ribonuclease $A$ does not cleave RNA molecules that are annealed to complementary DNA molecules. This property of the enzyme is exploited to identify mismatched RNA:DNA duplexes. When an RNA probe designed to complement the reference DNA sequence is annealed to a test sample, any mismatch will expose the RNA for cleavage (Myers et al., 1985a). If one labels the RNA probe in some way, the position of the cleavage site can be determined by sizing it by gel electrophoresis. The efficiency of this method is not as good as DGGE or CCM. Furthermore, synthesis of RNA probes is not a trivial matter and this method has been replaced by other scanning methods.

\section{Single Strand Conformation Polymorphism (SSCP)}

The three dimensional structure of single-stranded DNA is determined by its sequence and the environment it is in. Consequently, when the environment is held constant, any change in the DNA sequence alters its conformation. Therefore, as single-stranded DNA molecules are going down native (non-denaturing) gels during electrophoresis, molecules with different conformations migrate at different rates and are separated. Other factors affecting DNA conformation includes temperature, $\mathrm{pH}$, and buffer conditions can be used to exaggerate the conformational differences. In general, lower temperatures and $\mathrm{pH}$ preserve the conformation and make it easier to distinguish between DNA molecules with different sequence compositions (Hayashi, 1991).

A recent advance in this method is the combined use of fluorescent labels and capillary electrophoresis in SSCP analysis (Inazuka et al., 1997). By labeling the two DNA strands with different fluorescent dyes, one can examine both strands in the same experiment and improve the sensitivity of the method. The new capillary electrophoresis (CE) instruments have very fast separation times and are all equipped with automated sample loaders. Furthermore, because $C E$ is highly reproducible, it is possible to compare data from run to run by simple computer analysis, thereby increasing the power of the method. The advantages of SSCP are its technical simplicity and the fact that the variants can be isolated from the gel for further analysis. Its limitations include the diminishing influence of single nucleotide changes in molecules that are larger than $~ 300$ $\mathrm{bp}$ and the need to use multiple buffer conditions if one were to achieve $290 \%$ sensitivity (Sheffield et al., 1993; Hayashi and Yandell, 1993). 
Cleavase Fragment Length Polymorphism Analysis (CFLPA)

A variant of the SSCP method is CFLP analysis. Instead of the use of native gels to resolve single-stranded DNA of different conformations, this method takes advantage of the ability of a thermostable structure-specific endonuclease (Cleavase I) to recognize and cut the junction between single-stranded and double-stranded DNA regions, thereby capturing the secondary structures of the DNA molecules. Partial digestion of DNA strands in their native conformation by Cleavase I will produce multiple fragments that can be resolved on a sequencing gel. Each band reflects the presence of a hairpin structure and the intensity of the band reflects its stability in solution (and therefore its predominance in the partially digested mixture). Conformational differences due to DNA sequence variation between two samples result in banding pattern differences (Brow et al., 1996; Rossetti et al., 1997).

Because the secondary structures are detected by enzymatic cleavage, as visualized by banding patterns rather than by electrophoretic mobility of the whole molecule as one band (as in SSCP), CFLPA can be used to scan larger DNA fragments. However, the need for complex pattern analysis makes it more difficult to automate. Furthermore, over- and under-digestion of the fragments alters the number and size of bands, creating intractable problems for banding pattern comparisons. As with SSCP, CFLPA also suffers from the opposing requirements of keeping the complementary DNA strands apart while allowing each single stranded DNA to selfanneal to form a stable structure during the cleavage step.

\section{MutS Protein-binding Assays}

Proteins in the DNA mismatch repair pathway have been used in SNP discovery. The E. coli MutS protein recognizes and binds to heteroduplex DNA with up to 3 mismatched bases in a row. The use of a gel-shift assay provides a way to detect MutS binding and is the earliest version of a MutS-based polymorphism screening method (Lishanski et al., 1994). An improved binding assay utilizes MutS protein immobilized on magnetic beads to capture heteroduplex DNA labeled with biotin that is in turn detected by an enzyme-linked immunosorbent assay (ELISA), thereby increasing its sensitivity (Wagner et al., 1995). The MutS binding assay is one of just three non-gel based SNP scanning methods (Kwok, 2001). The major disadvantages of the MutS binding assay are the high false positive rate due to PCR errors and its inability to distinguish between different polymorphisms contained within the same DNA fragment.

\section{Mismatch Repair Detection (MRD)}

The E. coli methyl-directed mismatch repair system ensures the integrity of the DNA sequence by binding to heteroduplex DNA containing up to 3 nucleotides in length followed by nicking and digestion of the newly synthesized, unmethylated strand before resynthesis occurs (Modrich, 1991). The MRD method takes advantage of the inability of the system to repair loops of 5 nucleotides or greater (Parker and Marinus, 1992). If a test DNA fragment and a reference DNA fragment are cloned into vectors containing an intact lacZa gene or a disrupted lacZa gene containing a 5-bp insertion, respectively, colonies containing plasmids with intact lacZagene are blue whereas colonies containing the disrupted lacZa gene are white when grown in X-gal and IPTG. If the plasmids containing the intact lacZa gene are grown in a dam- bacterial strain, resulting in unmethylated blue plasmids while the plasmids containing the lacZa gene disrupted by a 5-bp insertion are grown in a dam+ bacterial strain, resulting in methylated white plasmids, the plasmid DNA derived from the test and reference samples can be linearized, denatured, and allowed to reanneal, resulting in unmethylated homoduplex from the test sample, methylated homoduplex from the reference, and hemimethylated heteroduplex from the annealing of test and reference samples. When treated with $\mathrm{Mbol}$ and Dpnl to digest the unmethylated and methylated homoduplexes, respectively, only the hemimethylated heteroduplex DNA remains intact. After circularization, the plasmid containing heteroduplex DNA is transformed into E. coli. Although all of the heteroduplex plasmids contain a 5-nucleotide loop in the lacZa gene, it is not repaired by the $E$. coli mismatch repair system unless a mismatch is present in the insert. Consequently, if there is no mismatch in the insert DNA, the plasmid will be replicated and yield a mixed colony containing blue and white cells with blue as the overall color. When a mismatch is present in the insert, however, the mismatch repair system will digest the unmethylated strand (containing the intact lacZa gene) and replicate only the strain containing the disrupted lacZa gene to yield a white colony (Faham and Cox, 1995).

The advantage of this method is its ability to detect mismatches in DNA fragments up to $10 \mathrm{~kb}$ in size. The drawbacks include a relatively high false positive rate of $10 \%$, the lack of information on mismatch location, and the many time consuming steps involved.

\section{T4 Endonuclease VII Cleavage of Heteroduplex DNA}

$\mathrm{T} 4$ endonuclease VII is a member of the resolvase family that cleave mismatched DNA heteroduplexes. When DNA heterduplexes are treated with T4 endonuclease VII, the double stranded DNA is cleaved at the sites of mismatch. The size of the cleavage product, as estimated by gel electrophoresis, provides information on the location of the mismatch (Youil et al., 1995; Youil, et al., 1996; Babon et al., 2000). The advantages of this method are its simplicity, the ability to scan larger DNA fragments, and the ability to localize the polymorphism. Its major drawbacks are that not all mismatches are cleaved efficiently and the background is relatively high.

\section{Heteroduplex Analysis (HA)}

Heteroduplex DNA fragments containing single nucleotide mismatches can be separated from their homoduplex counterparts on non-denaturing "Hydrolink" gels (Keen et al., 1991). This separation is due to the small differences between the electrophoretic mobility of heteroduplexes containing mismatches and that of their homoduplex counterparts. The main advantage of this method is its simplicity, but the need for a special gel matrix and its approximately $80 \%$ detection rate prevent the widespread 
use. With recent advances in capillary electrophoresis both in improvements of gel matrices and throughput, HA promises to be a more powerful method for SNP scanning (Ekstrom et al., 1999; Gao and Yeung, 2000; Tian et al., 2000).

\section{Denaturing High Performance Liquid Chromatography (DHPLC)}

Denaturing high performance liquid chromatography (DHPLC) is a variant of heteroduplex analysis. Instead of using a gel and separating the DNA fragments by electrophoresis, a modified resin and HPLC are employed for fragment analysis. When the DNA fragments are separated at elevated temperatures, partial melting occurs and the heteroduplex DNA containing mismatches will have a different retention time than the homoduplex DNA. Because HPLC is a robust technology and autosampling is used routinely, DHPLC is a very simple method to implement. With recent improvements in the melting curve prediction software, the method has high sensitivity and reproducibility (Underhill et al., 1997; Spiegelman et al., 2000; Huber et al., 2001). The only drawback is the somewhat limited throughput of the system, since samples are processed one at a time.

\section{UNG-Mediated T-Sequencing}

The uracil N-glycosylase (UNG) mediated sequencing method utilizes UNG to remove the uracil base from DNA amplified in the presencce of dUTP followed by cleavage of the molecule at the abasic sites by either endonuclease IV or sodium hydroxide. When the PCR primer is labeled and limiting amounts of dUTP are incorporated into a DNA fragment during PCR, incubation with UNG followed by cleavage produces a set of labeled fragments that gives a gel pattern identical to a "T" sequencing ladder. By comparing the banding pattern of two related samples, one can identify the variant sites. When both strands are examined, one can detect 10 out of the 12 possible single nucleotide base changes since they all involve the "T" base on one of the strands. Given the fact that $\mathrm{C}>\mathrm{G}$ and $\mathrm{G}>\mathrm{C}$ changes are relatively rare, this method has the potential of detecting $>90 \%$ of all single nucleotide polymorphisms (Hawkins and Hoffman, 1997; 1999; Vaughan and McCarthy, 1998).

Unlike Sanger DNA sequencing, where the DNA fragments are produced by a terminating event, the UNGmediated T-sequencing method examines full length DNA fragments and the size of the fragments scanned is limited only by the properties of the sequencing gel and instrument. Since current equipment can easily scan fragments up to $1,000 \mathrm{bp}$ in size, this is a clear advantage. Besides the fact that $\mathrm{G}>\mathrm{C}$ and $\mathrm{C}>\mathrm{G}$ changes are not detected, the results only give partial sequence information and both strands must be scanned to achieve an acceptable detection rate.

RNA-Mediated Finger printing with MALDI MS Detection A similar approach to the UNG-mediated T-sequencing is the RNaseCut (Krebs et al, 2003) strategy that uses RNase T1 and MALDI mass spectrometry to detect sequence variations. The method takes advantage of base-specific (the $\mathrm{G}$ base) digestion of RNase $\mathrm{T} 1$ and determination of the "G" pattern by mass spectrometry. In the experimental design, promoter sequences of RNA polymerase T3 and T7 are tagged on to the forward and reverse PCR primers respectively. After PCR, T3 and T7 RNA polymerases are used to transcribe the PCR products in separate reactions and followed by RNase T1 digestion of the transcripts. Since RNase digests any fragment that contains a $G$ base, the result of the digestion is a series of RNA fragments that ends with a $G$ base (like a bunch of restriction fragments). These single-stranded RNA fragments are relatively small and produce less complex MS patterns. Any sequence variation that involves a $G$ base will change the number and size of the fragments and are easily detected by MALDI MS. Sequence variations involving only $\mathrm{A} / \mathrm{U}$ bases will result in mass shifts that are at times not resolvable. The most attractive feature of this method is the speed of detection. Unlike other fragmentation methods (such as chemical cleavage, ribonuclease cleavage, etc.) that rely on electrophoresis to identify the patterns, MALDI MS is not as labor intensive or time consuming. In addition, the size pattern is precise and highly reproducible since RNase T1 does not under- or over-digest. The weakness of this method is that it is unable to detect all polymorphisms.

\section{Sequencing by Hybridization}

When the sequence of a DNA fragment is known, it is possible to array a set of short oligonucleotides representing the entire DNA fragment on a "DNA chip". Since the precise sequence of the oligonucleotide at each location on the chip is known, one can infer the DNA sequence of a fluorescently labeled DNA probe by analyzing the pattern of hybridization (Pease et al., 1994). With current technology, one can scan $>15 \mathrm{~kb}$ of DNA on a chip containing 40,000 oligonucleotides. In principle, one can compare the hybridization pattern generated by different DNA samples to identify all DNA variations among them. These samples can be a few long-range PCR products or cloned DNA fragments, or a large collection of small PCR products.

The major advantage of this method is that a large DNA fragment (or a large number of small DNA fragments) can be scanned in one hybridization reaction. This method is therefore best suited for analysis of long-range PCR products to identify mutations and polymorphisms in known genes, where its ability to scan for mutations is unparalleled (Hacia et al., 1996; 1998; Cargill et al., 1999; Halushka et al., 1999). The drawbacks of the method include the fact that one must know the precise DNA sequence of the DNA fragments under study, the expense involved in DNA chip design and development, and the lack of resolving power when a sequence is duplicated in the region being scanned.

\section{Direct DNA Sequencing}

Until very recently, direct DNA sequencing was laborious and expensive. With the development of better DNA polymerases and sequencing chemistries, DNA sequencing as a scanning method for SNPs is highly competitive when compared to all the methods described above. The recently-developed mutant Taq DNA 
polymerase containing an F667Y mutation vastly improved the DNA sequence quality because of its ability to incorporate the chain terminating dideoxyribosenucleoside triphosphates (ddNTPs) and their fluorescently labeled analogs at rates that are similar to those for the natural deoxyribosenucleoside triphosphates (dNTPs) (Tabor and Richardson, 1995).

Prior to the general use of automated DNA sequence analyzers and fluorescent DNA sequencing, a simple technique of sequence comparison was to load all the " $A$ ", "C", "G", and "T" sequencing reactions of the samples being tested side-by-side so that one could scan the autoradiograms by inspection. The presence of polymorphisms is represented by missing or additional bands in the sequencing ladder. Because the human eye is very good at pattern recognition, and one is focused on a break in the pattern across many samples (rather than the individual DNA sequence per se), the quality of the sequencing data is the only limitation of its sensitivity. This simple technique has been adapted for fluorescent DNA sequencing using a single dye-labeled primer and is named "orphan peak analysis" (Hattori et al., 1993).

Using automated DNA sequence analyzers, the basecalling software can assign the DNA sequence automatically and the resultant sequence can be compared to other sequences by homology search programs. If the quality of the DNA sequencing data is good, and if both alleles of an SNP are found among the homozygous samples, the SNP can be spotted very effectively. If only one of the alleles is present among the homozygous samples being examined, heterozygous samples must be distinguished from the homozygous samples before an SNP can be identified. Under these circumstances, one can compare the sequencing traces from different individuals and look for differences in the peak pattern.

In four-color fluorescent sequencing, one can either use a set of dye-labeled primers or a set of dye-labeled ddNTP chain terminators. The peak pattern of the sequencing traces with the use of the dye-primer sequencing chemistry with the mutant Taq polymerase (commercially available as AmpliTaq, FS and ThermoSequenase) is very even (Nickerson et al., 1997). Given the nice sequencing pattern, a polymorphic base in a heterozygous DNA sample is represented by two superimposed base peaks, each at about half the peak height as those for the peaks found in the rest of the sequence. Because the bases are quite similar in size to each other, the base-calling software is unable to assign a base to the position unambiguously in most cases. A rudimentary single nucleotide polymorphism/mutation program has been developed recently to identify these polymorphisms automatically (Nickerson et al., 1997; Rieder et al., 1998). To avoid the extra expense of labeling the sequencing primers with fluorescent dyes, one can add the M13 universal and reverse primer sequence to the PCR primer sequences (at a more moderate cost), such that the PCR products produced contain the necessary priming sites for sequencing using dye-labeled universal primers.

Although dye-labeled ddNTP terminator sequencing chemistry produces sequencing traces with less even peaks (Kwok et al., 1994; Parker et al., 1996), the newer terminators such as the dichlororhodamine and energy transfer terminators give relatively even peaks (Zakeri et al., 1998). With improvements in polymorphism scanning software, the day will soon come when one can compare DNA sequences from different samples and identify, with great accuracy, all single nucleotide polymorphisms.

A recent variation of detecting polymorphisms by comparative DNA sequencing (called polymorphism ratio sequencing) is done by labeling two DNA sequencing reaction products with different color schemes and loading the two samples onto one capillary/lane for electrophoresis. For example, base "A" and base "C" of the reference DNA are labeled with blue and green colors, respectively, while the same two bases of the test DNA are labeled with yellow and red colors, respectively. When the two samples are pooled and loaded onto the same capillary/lane together during electrophoresis, every base will have two colors if the two samples have identical DNA sequence. When a polymorphism is present, and both individuals are homozygous, the particular peak has only one color. By subtracting the intensities of the colors of one individual from the other, polymorphisms can be identified quite easily. The method is very sensitive and can be used to detect both SNPs and insertion/deletions. The weakness of the method is that each capillary detects only two bases. In order to detect all four bases, one needs to perform four separate sequencing reactions, pool and load them onto two capillaries.

The greatest advantage in SNP detection by direct DNA sequencing is the complete information it yields. In one experiment, the type, the location, and the sequence context of each polymorphism are completely determined. The disadvantages, including the need for high quality amplified DNA samples, added expense when universal primer sequences are added to PCR primers, and expensive automatic sequence analyzing instruments, are becoming easier to overcome. For example, simple and reliable methods for post-PCR clean-up by either gel purification or enzymatic degradation of excess PCR primers and dNTPs have been used successfully to yield good sequencing templates (Hanke and Wink, 1994). The major drawback of this method is that only about $400 \mathrm{bp}$ of high quality sequencing data are routinely generated by DNA sequencing, although one can scan $\sim 800$ bp of DNA in a large PCR product by sequencing from both directions.

\section{Technologies For Genotyping Known SNPs}

The ideal genotyping method must be easily and reliably developed from sequence information, robust, inexpensive, flexible, automated, and produces data that are easily analyzed. Although no such ideal genotyping method exists, a number of promising SNP genotyping methods are currently available and further improvements in biochemistry, engineering, and analytical software will bring the existing methods closer to the ideal. The evolution of SNP genotyping technologies is characterized by improvements in the three aspects of the genotyping process: allelic discrimination, reaction format, and signal detection. 
While all the SNP scanning methods described above are capable of producing genotyping data, they are not acceptable approaches to genotyping because they are either too expensive to implement, or one is never certain if the inferred genotyping is the true genotype because the allelic discrimination reaction is not sequence specific.

Sequence specific detection relies on four general mechanisms for allelic discrimination: allele-specific hybridization, allele-specific nucleotide incorporation, allelespecific oligonucleotide ligation, and allele-specific invasive cleavage (Kwok, 2000). All four mechanisms are reliable but each has its pros and cons.

\section{Hybridization}

With the hybridization approach, two allele-specific probes are designed to hybridize to the target sequence only when they match perfectly. Under optimized assay conditions, even one-base mismatches destabilize the hybridization sufficiently to prevent the allelic probe from annealing to the target sequence. Because no enzymes are involved in allelic discrimination, hybridization is the simplest mechanism for genotyping. The challenge lies in designing allele-specific probes that can distinguish one-base mismatches. With ever more sophisticated probe design algorithms and the use of hybridization enhancing moieties such as DNA minor groove binders, allele-specific probes can be designed with high success rate.

When the allele-specific probes are immobilized on a solid support, labeled target DNA samples are captured and the hybridization event is visualized by detecting the label after the unbound targets are washed away. Knowing the location of the probe sequences on the solid support allows one to infer the genotype of the target DNA sample (Wang et al., 1998). Allele-specific hybridization is also the basis of several elegant homogeneous genotyping assays. These assays differ in the way they report the hybridization event. In the 5'-nuclease assay, a probe annealed to target DNA being amplified is cleaved during PCR. Monitoring the cleavage event is therefore a way to determine whether hybridization has occurred (Livak, 1999). With molecular beacon detection, hybridization to target DNA opens up the stem-loop structure. Determining the open-closed status of the stem-loop structure is therefore a way to figure out if hybridization has occurred (Kostrikis et al., 1998; Tyagi et al., 1998). With "light-up" probes, the thiazole orange derivative linked to a peptide nucleic acid (PNA) oligomer fluoresces only when the PNA oligomer hybridizes specifically to complementary nucleic acids (Svanvik et al., 2000). Fluorescence is therefore evidence for hybridization.

\section{Primer Extension}

Primer extension is a very robust allelic discrimination mechanism. It is highly flexible and requires the smallest number of primers/probes. Probe design and optimization of the assay are usually very straightforward. There are numerous variations in the primer extension approach based on the ability of DNA polymerase to incorporate specific deoxyribose nucleosides complementary to the sequence of the template DNA. However, they can be grouped into 3 categories. First is a sequencing (allelespecific nucleotide incorporation) approach where the identity of the polymorphic base in the target DNA is determined. Second is an allele-specific PCR approach where the DNA polymerase is used to amplify the target DNA only if the allele-specific PCR primers are perfectly complementary to the target DNA sequence. Third is allelespecific primer extension approach where one or a handful of bases are incorporated only if the 3 '-end of the allelespecific probe matches the polymorphic base in the target sequence.

In the sequencing approach, one can either determine the sequence of amplified target DNA directly by mass spectrometry or perform primer extension reactions with amplified target DNA as template and analyze the products to determine the identity of the base(s) incorporated at the polymorphic site (Laken et al., 1998; Pastinen et al., 1997). A number of ingenious ways have been devised for primer extension product analysis in homogeneous assays. Most of these approaches combine novel nucleic acid analogs and monitoring of interesting differences in physical properties between starting reagents and primer extension products (Chen and Kwok, 1997; Chen et al., 1997; 1999).

In the allele-specific PCR approach, one relies on the DNA polymerase to extend a primer only when its 3 '-end is perfectly complementary to the template. When this condition is met, a PCR product is produced. By determining whether a PCR product is produced or not, one can infer the allele found on the target DNA. Several innovative approaches have been utilized to detect the formation of specific PCR products in homogeneous assays. Some are based on melting curve analysis and some are based on hybridization of target specific probes (Germer and Higuchi, 1999; Myakishev et al., 2001). A variation of this approach is the allele-specific primer extension. Here, the PCR product containing the polymorphic site serves as template and the 3 '-end of the primer extension probe consists of the allelic base. The primer is extended only if the 3'-base complements the allele present in the target DNA. Monitoring the primer extension event therefore allows one to infer the allele(s) found in the DNA sample (Pastinen et al., 2000).

\section{Ligation}

DNA ligase is highly specific in repairing nicks in the DNA molecule. When two adjacent oligonucleotides are annealed to a DNA template, they are ligated together only if the oligonucleotides perfectly match the template at the junction. Allele-specific oligonucleotides can therefore be made to interrogate the nature of the base at the polymorphic site. One can infer the allele(s) present in the target DNA by determining whether ligation has occurred or not. While ligation has the highest level of specificity and is easiest to optimize among all allelic discrimination mechanisms, it is the slowest reaction and requires the largest number of modified probes. However, ligation as a mechanism has the potential of genotyping without need for prior target amplification by PCR. This can be accomplished by either the ligation chain reaction (LCR) (Barany, 1991) or by the use of ligation (padlock) probes that circularize by DNA ligase followed by rolling circle signal amplification (Lizardi et al., 1998; Baner et al., 1998). 


\section{Invasive Cleavage}

Structure-specific enzymes cleave a complex formed by the hybridization of overlapping oligonucleotide probes. When probes are designed such that the polymorphic site is at the point of overlap, the correct overlapping structure is formed only with the allele-specific probe but not with the probe with a one-base mismatch. Elevated temperature and an excess of the allele-specific probe enable multiple probes to be cleaved for each target sequence present in an isothermal reaction. In an innovative application of this method, the flaps from the cleaved allele-specific probes are used in a second reaction where a labeled secondary probe is cleaved. This signal amplification step helps boost the amount of labeled cleavage product produced to $10^{6}$ to $10^{7}$ per target sequence per hour, an amount sufficient for detection without the need for a target amplification process such as PCR (Hall et al., 2000).

The major advantages of this approach are the isothermal nature of the reaction and the potential for genotyping without PCR amplification. There are a number of technical issues that need further refinement. First, the amount of genomic DNA needed in the reaction is high. Second, the purity of the marker specific probes must be extremely high or non-specific reactions become problematic. Third, probe design is somewhat tricky because the sequential reactions have to work under the same conditions but the sequence context of the SNPs is fixed. With improvements in probe design algorithms and further development, these technical concerns will likely be overcome.

\section{Reaction Formats}

Starting with genomic DNA, each genotyping method undergoes a series of biochemical steps and a product detection step. The reaction format mostly reflects the requirements of the detection modality. In general, biochemical reactions are more robust in solution but capturing the reaction products on solid support allows for detection in parallel and increases the throughput substantially.

\section{Homogeneous Reactions}

A number of innovative genotyping methods are done in solution from beginning to end and are therefore designated as homogeneous reactions. Some of them require no further manipulations once the reaction is set up initially. Others call for a number of reagent addition steps but no separation or purification steps are needed. Homogeneous assays are usually robust, highly flexible and not labor intensive. The major drawback is the limited amount of multiplexing one can do with homogeneous assays.

\section{Reactions on Solid Support}

Solid supports used in genotyping can be a latex bead, a glass slide, a silicon chip, or just the walls of a microtiter well. In some cases, marker specific oligonucleotides are placed on the solid support and the allelic discrimination reaction is done on the support; in other cases, generic oligonucleotides are placed on the solid support and they are used to capture complementary sequence tags conjugated to marker specific probes. In the former strategy, the oligonucleotide arrays act as a collection of reactors where the target DNA molecules find their counterparts and the allelic discrimination step for numerous markers proceeds in parallel. In the latter, the arrayed oligonucleotides are used to sort the products of the allelic discrimination reactions (also done in parallel) performed in aqueous solution. In both cases, the identity of an oligonucleotide on a latex bead or at a particular location on the microarray (on a glass slide or silicon chip) is known and the genotypes are inferred by determining which immobilized oligonucleotide is associated with a positive signal. The major advantage of performing genotyping reactions on solid supports is that many markers can be interrogated at the same time. Besides savings in time and reagents, performing numerous reactions in parallel also decreases the probability of sample/results mix-ups. The drawback of performing genotyping reactions on solid support is that design of the oligonucleotide arrays and optimization of the multiplex reactions require substantial capital and time investment. With better algorithms for multiplex PCR design, this limitation may be alleviated in the near future.

\section{Detection Mechanisms}

Detection of a positive allelic discrimination reaction is done by monitoring the light emitted by the products, measuring the mass of the products, or detecting a change in the electrical property when the products are formed. Numerous labels with various light-emitting properties have been utilized in detection methods based on light detection. In general, only one label with ordinary properties is needed in genotyping methods where the products are separated or purified from the excess starting reagents. For homogeneous reactions, where no separation or purification is needed, the property of the label has to be changed when a product is formed. This usually requires interaction of the label with another component of the reaction when a product is formed. A number of elegant genotyping methods are developed to take advantage of certain physical characteristics of the labels.

Monitoring light emission is the most widely used detection modality in genotyping and there are many ways to do so. Luminescence, fluorescence, time-resolved fluorescence, fluorescence resonance energy transfer (FRET), and fluorescence polarization (FP) are useful properties of light utilized in a host of genotyping methods.

\section{Luminescence Detection}

Luminescence is emitted in an ATP-dependent luciferase reaction. When ATP production is coupled with a primer extension reaction, luminescence is observed every time a deoxyribosenucleoside is added in the primer extension reaction. Because the background is extremely low, luminescence has a very good signal to noise ratio. However, the additional enzymatic steps and substrates required complicate the experimental procedure and increase the cost of the assay.

\section{Fluorescence Detection}

Fluorescence detection is straightforward and easy to implement. Besides using it in a setting of capturing 
fluorescent labels on a solid support or separating the fluorescent product from the label by gel or capillary electrophoresis, fluorescence detection can be used to monitor the formation of double stranded DNA with a DNA intercalating dye that only fluoresces in the presence of double stranded DNA. Direct fluorescence detection is very versatile and can be done in multiplex to a certain extent. However, the need for product purification or separation when fluorescent labels are used and the interference by non-specific double stranded DNA species when intercalating dyes are used are some of the drawbacks of direct fluorescence detection.

\section{Time-Resolved Fluorescence Detection}

Time-resolved fluorescence as a detection approach is feasible when the emission half-life of the fluorescent dye is long. With this class of dyes (mostly compounds of rare earth elements such as Lanthanides), the fluorescence reading is done sufficiently long after excitation such that autofluorescence (which has a very short half-life) is not observed (Hansen et al., 1995; Kirschstein et al., 1999). The background in time-resolved fluorescence detection is almost non-existent so that this is a very sensitive detection modality. The drawback is that the lanthanides are inorganic compounds that cannot be used to label nucleic acids directly. An organic chelator conjugated to the probe must be used to bind the lanthanides in the reaction.

\section{Fluorescence Resonance Energy Transfer}

Fluorescence resonance energy transfer is a popular detection method in homogeneous genotyping assays. FRET occurs when two conditions are met. First, the emission spectrum of the fluorescent donor dye must overlap with the excitation wavelength of the acceptor dye. Second, the two dyes must be in close proximity to each other because energy transfer drops off quickly with distance. The proximity requirement is what makes FRET a good detection method for a number of allelic discrimination mechanisms. Basically, any reaction that brings together or separates two dyes can use FRET as the detection method. FRET detection has therefore been used in primer extension and ligation reactions where the two labels are brought into close proximity to each other. It has also been used in the 5'-nuclease reaction, the molecular beacon reaction, and the invasive cleavage reactions where the neighboring donor/acceptor pair is separated by cleavage or disruption of the stem-loop structure that holds them together (Livak, 1999; Kostrikis et al., 1998; Tyagi et al., 1998; Hall et al., 2000). The major drawback of the method is the cost of the labeled probes required in all the genotyping approaches with FRET detection. In the cleavage approaches, the probes are doubly labeled, increasing the cost of the probe synthesis even further.

\section{Fluorescence Polarization}

Fluorescence polarization (FP) has been used in clinical diagnosis and numerous binding assays for years but its use as a detection method for SNP genotyping has a very short history. This is because instruments sensitive enough for detecting small amounts of dyes are not available until recently. When a dye is excited by plane polarized light, the emitted fluorescence is also polarized. The degree of polarization is determined by temperature, viscosity of the solvent, and the molecular volume of the fluorescent molecule. All these factors affect molecular motion and, in general, the faster a molecule tumbles and rotates in solution, the less polarized is its fluorescence. Because molecular volume is proportional to molecular weight, fluorescence polarization is therefore a good method to detect changes molecular weight. In principle, any genotyping method in which the product of the allelic discrimination reaction is substantial larger or smaller than the starting fluorescent molecule can use FP as a detection method. Indeed, FP has been used as the detection method in the primer extension reaction where small fluorescent dye terminators are incorporated into a larger probe (Chen et al., 1999). Furthermore, FP has been shown recently that it is a good detection method in the 5'-nuclease reaction where small fluorescent molecules are formed when large fluorescent probes are cleaved in the reaction (Latif et al., 2001). FP can also be used as a detection method for the invasive cleavage reaction where the large fluorescent signal probe is cleaved, producing a small fluorescent tag (Hsu et al., 2001b). The advantages of the FP detection method include the much smaller amount of fluorescent dyes needed compared to FRET or direct fluorescence detection methods, cheaper probes used, and the potential for utilizing the full visible spectrum in multiplex reactions. The drawback is mainly that any non-specific products will increase the noise in the signal.

\section{Mass Spectrometry}

Unlike all other detection methods that infer the identity of the products generated in the allelic discrimination reaction by monitoring the fate of some label, mass spectrometry (MS) measures the molecular weight of the products formed and is therefore the most direct method of detection. Because MS determines the fundamental property of the DNA molecule, no labels are needed. High resolution MS can easily distinguish between DNA molecules that differ by only one base (Ross et al., 1998; Liet al., 1999; Berlin and But, 1999; Buetow et al., 2001). A further advantage of MS is that it takes only milliseconds to analyze each sample so even though MS analyzes each sample serially, the throughput is still very high. Furthermore, by appropriately designing the probes, moderate multiplexing is possible (Ross et al., 1998). The main disadvantage of the MS detection method is the exquisite purity the analyte has to be for it to work. With further refinement of the product purification process, it may be possible to overcome this drawback.

\section{Electrical Detection}

A promising detection method is one that monitors a change in the electrical properties of the products of the allelic discrimination reaction. Currently, this is done on solid support where oligonucleotides are deposited on electrodes (Cornell et al., 1997; Wang et al., 1997). The electrical property of the probe is altered when the DNA complementary to the probe is annealed to it. This is 
exaggerated if a ferromagnetic label is used. Electrical detection combines semiconductor technology with biochemistry and eliminates the need for light detection or extensive product processing. This area is still in its infancy and there are still a number of biochemical and engineering obstacles to overcome before the throughput of genotyping methods based on this detection mechanism is high enough and the cost low enough for its wide acceptance.

\section{Examples of SNP Genotyping Methods}

A number of SNP genotyping methods will be discussed in some detail here to highlight how the allelic discrimination mechanisms, reaction formats, and detection modalities can be combined in various ways to produce the most promising SNP genotyping approaches in use today. It illustrates how the SNP genotyping methods evolve by adopting new technologies from other fields.

\section{Microarray Genotyping (Hybridization on Solid Support With Fluorescence Detection)}

The first large scale genotyping method was developed jointly by the Whitehead Institute and Affymetrix, Inc. (Wang et al., 1998) The GeneChip HuSNP Mapping Array contains 1,494 SNPs that can be genotyped in one experiment (Mei et al., 2000). The major breakthrough of this approach is the degree of multiplexing achieved by designing PCR assays that amplify very small products and a second round of PCR with a common set of primers. In the current version of the assay, the entire set of 1,494 SNPs is amplified in just 24 multiplex reactions (average of 62 SNPs in one multiplex reaction). In a rather long protocol, the PCR products are pooled, concentrated, hybridized to the DNA microarray, stained, and visualized. Because each SNP is interrogated by a set of "tiling" oligonucleotides, the genotypes called are quite accurate. Other advantages of this approach include a low requirement for starting genomic DNA (120 ng total for all 1,494 markers), large number of SNPs typed in one experiment, and minimal manual steps. The major drawback of this approach is that because the design and manufacture of the microarray is quite expensive, the set of markers selected cannot be changed quickly or arbitrarily. Furthermore, it is a common experience that about $20 \%$ of the SNPs on the HuSNP chip does not yield confident results. This level of failure rate is too high for many applications.

Another assay based on hybridization on solid support is the DASH (dynamic allele-specific hybridization) assay (Howell et al., 1999). Instead of monitoring the hybridization at a constant temperature, this approach looks for the melting temperature differences between matched and mismatched targets when annealed to an allele-specific probe by monitoring the hybridization over a range of temperatures. Using a DNA intercalating dye such as Sybr Green I that fluoresces in the presence of double-stranded DNA, fluorescence is observed only when hybridization occurs and double-stranded DNA species are formed. With recent improvements in probe design, DASH assays can now be designed for near $100 \%$ of SNPs that can be uniquely amplified by PCR (Prince et al., 2001). The specificity and robustness of the assay come with a price.
Because double-stranded DNA species will cause the dye to fluoresce, the PCR products have to be rendered singlestranded. This is accomplished by biotinylating one of the PCR primers and capturing the biotinylated PCR product on solid support followed by denaturing and washing away the unlabeled strand of PCR product. Furthermore, the single reporter used means that two reactions must be run in parallel for each SNP.

\section{Molecular Beacon Genotyping (Homogeneous} Hybridization With FRET Detection)

Molecular beacons are stem-loop structures that hold a fluorescent reporter in close association with a universal quencher such that fluorescence is only observed when the stem-loop structure opens up (Kostrikis et al., 1998). With proper design, a DNA target that is perfectly complementary to the sequence of the loop portion of the molecular beacon hybridizes to the molecular beacon and forces open the stem, leading to the emergence of fluorescence. The molecular beacon with a one base mismatch will not hybridize to the target strongly enough to disrupt the stem-loop structure and no fluorescence is observed (Tyagi et al., 1998). Because the presence or absence of fluorescence reflects the open or close status of the stem-loop structure, no purification or separation steps are needed. In fact, once the assay is set up, no more manual manipulations are needed. As long as one can monitor the fluorescence, one can infer the genotype of the DNA target. This "closed-tube" system has real advantages because cross contamination is minimized and automation is easily achievable. An added advantage is that when real-time fluorescence monitoring is possible, the assay can be used to quantify the amount of DNA present in an unknown sample. With many fluorescent dyes available in the visible spectrum, multiplex analysis is possible to some extent. The one drawback of this approach is the cost of the two doubly labeled molecular beacons needed for each SNP marker. Until design algorithms are perfected, there is a fraction of molecular beacons that will not work without optimization.

\section{5'-Nuclease Assay (Homogeneous Hybridization With FRET or FP Detection)}

Taq DNA polymerase possesses a 5'-nuclease activity that displaces and cleaves oligonucleotides hybridized to a DNA segment undergoing replication. Based on this observation, the TaqMan assay was developed with a doubly labeled probe consisting of a reporter fluorescent dye and a minor groove binder (MGB)/universal quencher complex (Livak, 1999). The TaqMan probes are designed to hybridize during the extension phase of PCR only to the perfectly matching DNA target but not to that with a one-base mismatch. Cleavage of the hybridized probe separates the quencher from the reporter and fluorescence is observed. One can therefore infer the genotype of a test sample by monitoring the fluorescence of the reaction mixture. Recently, fluorescence polarization has been shown to be a good detection method for this assay (Latif et al., 2001). Because the starting probe has a much higher molecular weight than the cleavage products, the fluorescence polarization changes drastically in a positive reaction. Just like the 
molecular beacon assay, the TaqMan assay is a "closedtube" system and can be used for quantification of unknown DNA samples. This assay has been in use and thoroughly tested over several years now. With a number of improvements in assay design such as the incorporation of the minor groove binder that enhances the discriminating power between the TaqMan probes and more reliable primer design algorithms, the assay is easier to optimize. The cost of the labeled probes is the main obstacle to the widespread adoption of this method by the average laboratory.

\section{Allele-Specific PCR (Homogeneous Primer Extension With} Fluorescence or FRET Detection)

Allele-specific PCR has been used for quite some time to genotyping SNPs. It is a relatively simple technique and, when coupled with gel analysis, the genotypes can be called easily. Because the products are of the same size, two parallel reactions must be performed for each marker when gel electrophoresis is used as the detection method. Since there is no way to control for false negative results, allele-specific PCR is not used in large-scale projects. Everything changed when three groups came up with novel ways to detect PCR products in homogeneous solution.

Germer and Higuchi put together several recent advances to achieve single-tube genotyping by allelespecific PCR (Germer and Higuchi, 1999). First, a DNA intercalating dye was used to detect the presence of double-stranded DNA. Second, real-time fluorescence detection was used to determine the melting curve of a PCR product. Third, a GC-rich sequence was added to one of the allele-specific PCR primers to increase the melting temperature of one of the PCR products. Fourth, the stoffel fragment of Taq polymerase with two important attributes for allele-specific PCR was used in this method. Under the assay conditions, the stoffel fragment of Taq polymerase only extends the primer where the 3 '-end matches the target sequence and will only yield amplicons $<100$ bps. Taken together, these 4 advances allows for highly specific PCR amplification, with the resulting products easily distinguishable by melting curve analysis. Because both alleles can be assayed in the same reaction, this is another "closed tube" method where one has to set up the reaction and the instrument will take care of the rest. The advantage of this method is the low cost of the unlabeled primers and the simplicity of the assay. The only drawback is that not all SNPs can be assayed by this method because of the requirement that the amplicons be small. Under the best of circumstances, kinetic PCR cannot be designed for about $20 \%$ of SNPs.

Todd et al. (2000) developed a method based on the ability of a DNA enzyme that can cleave an RNA-containing reporter probe. Specifically, the antisense sequence of a 10-23 DNAzyme is added to one of the PCR primers for the assay such that the active DNAzyme is formed only if PCR amplification occurs. A DNA/RNA chimeric reporter substrate containing fluorescent and quencher dye molecules on opposite sides of the cleavage site is added to the reaction mixture and is cleavage as the DNAzyme forms during PCR amplification. The accumulation of PCR products is monitored in real time by changes in the fluorescence released by the separation of fluoro/quencher dye molecules as the newly formed DNAzyme cleaves the reporter substrate. The DzyNA-PCR DNA detection is novel and attractive because the only specialty reagent, the energy transfer DNA/RNA hybrid reporter substrate of the DNAzyme, can be used in any assay. The only target specific reagents are the two PCR primers, with one modified with the antisense sequence of the DNAzyme. Because this assay can be monitored in real time, DNA quantification is possible. At this point, the limitation of this assay is that only one reporter substrate is used and SNP genotyping has to be done in parallel reactions.

Myakishev et al. (2001) recently described a similar method in which the two allele-specific PCR primers are tailed with sequences that introduce priming sites for universal energy-transfer-labeled primers. The energytransfer-labeled primer contains a reporter dye that is quenched by a universal quencher in its natural stem-loop structure. When allele-specific PCR products are formed, the priming site is formed and the energy-transfer-labeled primer is extended. The extension product serves as template for the next round of PCR and the stem-loop structure is opened up as PCR proceeds, thereby releasing the reporter dye from the quencher and fluorescence is observed (Myakishev et al., 2001). Like kinetic PCR, only one reaction is required for each SNP and it is done in a "closed tube" format. With one set of universal energytransfer-labeled primers that can be used for any assay, this approach is quite cost-effective.

All three allele-specific PCR methods have nice features and are relatively inexpensive to develop. However, allele-specific PCR cannot be designed for every SNP because of local sequence constraints and the possibility of multiplex reaction is very limited, if not impossible.

Allele-specific Primer Extension (Primer Extension on Solid Support With Fluorescence Detection)

Instead of performing allele-specific PCR, one can utilize allele-specific primers to detect the presence or absence of a SNP within a PCR product. Because the PCR step is separated from the allele detection step, this method is more versatile and has two levels of specificity. It is therefore very robust and assays can be designed for almost all SNPs. In a recently described rendition of this method, some clever modifications were made to simplify the reaction procedure (Pastinen et al., 2000). By attaching a T7 RNA polymerase promoter sequence to one of the PCR primers, RNA templates are generated from the PCR products. The RNA templates then serve as the target in an allele-specific primer extension reaction mediated by a reverse transcriptase. Dye-labeled rNTPs are used in the reaction and they are incorporated when the immobilized allele-specific primer's 3'-base matches the allele found on the RNA template. Because of the large number of RNA templates produced by the T7 RNA polymerase and multiple dye-labeled rNTPs incorporated, very small amounts of PCR products are needed. The approach solved some of the problems that plagued solid phase primer extension reaction in the past, namely, the need for PCR product purification and generation of single-stranded 
DNA template for robust reaction. The good attributes of this approach include simple reaction procedure, small reaction volume, and low requirements for genomic DNA templates. The reaction mixture is complex, however, with multiple enzymes and specialty rNTPs.

\section{Arrayed Primer Extension (Primer Extension on Solid} Support With Fluorescence Detection)

Unlike allele-specific PCR, which assays for the presence or absence of a PCR product, the "generic" primer extension approach assays for the specific nucleotide being incorporated onto the primer at the polymorphic site. In the arrayed primer extension (APEX) approach (Shumaker et al., 1996; Pastinen et al., 1997; Dubiley et al., 1999; Tonisson et al., 2000), oligonucleotides which sequences correspond to the those neighboring the polymorphic sites of their corresponding SNPs are immobilized via their 5'end on glass surface. These probes are extended by one base in the presence of PCR products containing the SNP sequences. With each of the four dideoxy terminators labeled with different fluorescent dyes, the identity of the incorporated base can be inferred easily. Using fluorescence imaging techniques, the genotypes can be determined simply by noting the colors found on the various spots on the array. The APEX assay is quite robust and can be multiplexed. Furthermore, a universal master mix containing the four dye-terminators and DNA polymerase is used for all SNPs, making it a very simple reaction to set up. The challenge is that thermal cycling is generally not easily achieved in solid phase reactions so single stranded templates are needed for robust primer extension. This requires a larger amount of $\mathrm{PCR}$ products as target and a strand separation step that increases the cost of the reaction. In addition, placing SNP-specific probes on the solid support decreases the flexibility of the approach.

\section{Homogeneous Primer Extension Assays (With FRET or} FP Detection)

These approaches take advantage of the fact that dyelabeled terminators are incorporated covalently onto an oligonucleotide as the reaction proceeds. If a donor dye is found on the probe, excitation of the donor dye will cause the acceptor dye attached to the incorporated terminator to fluoresce (Chen and Kwok, 1997). Observation of FRET is therefore an indication that primer extension has occurred. With two different acceptor dye-labeled terminators, the genotype of a sample can be determined in one reaction (Chen et al., 1997). When a thermostable DNA polymerase is used and the fluorescence monitored in real-time, the assay is very sensitive and robust. However, the dye-labeled probe is relatively costly.

The primer extension reaction increases the molecular weight of the dye-terminator greatly when it is incorporated onto the oligonucleotide probe. This change is reflected in the FP value observed. When the reaction is driven to completion, the FP value is maximally increased and the genotypes can be determined easily (Chen et al., 1999). Because the probe is unlabeled and is used only to add molecular weight to the primer extension product, the start up cost of the assay is among the cheapest of all genotyping assays in use to date. With highly sensitive instruments available for FP detection readily available, the throughput of this assay can be very high.

The major drawback of the homogeneous primer extension assays is the need to degrade the excess PCR primers and dNTPs after the PCR step. This is necessary because the primers and dNTPs will interfere with the primer extension reaction. In the current reaction protocol, the excess primers and dNTPs are degraded enzymatically with exnonucleoase I and shrimp alkaline phosphatase. After a short incubation, the enzymes are heat-inactivated before the primer extension reaction mix is added and the reaction is allowed to proceed. Although the possibility for multiplex reaction is quite limited, the versatility and simplicity of the assay, with minimal requirements for optimization make the assay an attractive choice for many applications (Hsu et al., 2001a).

Primer Extension With Detection by Mass Spectrometry Mass spectrometry, a method well suited for detection of small DNA molecules, has been used as a detection method for a number of primer extension genotyping assays. It is used for both the "generic" primer extension reaction and the allele-specific primer extension reactions.

To date, the most successful applications of MS detection in the primer extension reaction are found in the biotechnology industry. For example, Ross et al. utilize matrix assisted laser desorption/ionization time-of-flight mass spectrometry (MALDI-TOF MS) to detect primer extension products in multiplex (Ross et al., 1998). Because the mass resolution is high, the few mass units differentiating between the primer extension products of the two alleles can be distinguished handily. By careful design of the primers used in the primer extension reaction to make sure that all the extended and unextended primers are in well-resolved mass windows, they can genotype 12 SNP markers in one multiplex PCR/primer extension/MS detection sequence. Buetow et al. (2001) describe a variation of the "generic" primer extension method in which only one dideoxyterminator is used in the reaction such that the primer extension products for the two alleles differ by at least one base (over 300 mass units). Unlike methods that depend on some form of fluorescence detection, no labeling is necessary in MS detection. The intrinsic mass differences between the primer extension products are assayed. Although MS is highly accurate and a moderate degree of multiplex is possible, there are a number of obstacles that need to be overcome. First and foremost is that the MS instrument can only handle one sample at a time. Even with multiplex PCR, each MS instrument will probably not be able to genotype more than a 20,000 marker-assays per day. Another important issue with MS detection is the need for purified samples that are free from ions and other impurities. This increases both the cost and time required for sample processing. However, many talented groups are working to improve the approach and these obstacles may be overcome in the near future.

Pyrosequencing (Homogeneous or Solid Phase Primer Extension With Luminescence Detection)

Pyrosequencing is a relatively new DNA sequencing method based on detecting the formation of pyrophosphate, 
the by-product of DNA polymerization (Ronaghi, 2001). When DNA polymerase takes a deoxynucleoside triphosphate and incorporates it onto the extending primer, pyrophosphate is formed. By a number of cleverly designed enzymatic steps, the pyrophosphate is converted to ATP that fuels a luciferase reaction (Nordstrom et al., 2000; Ahmadian et al., 2000). Therefore, light is observed when a nucleotide is added to the growing chain of DNA. Because stepwise addition of nucleoside triphosphates is needed in this procedure, it is very difficult to utilize this method to give long sequencing reads. It is a robust method for the primer extension detection, especially if there are a number of closely spaced SNPs (as in HLA typing). The major advantage of this method is the fact that, if needed, multiple bases in the vicinity of the polymorphic site can be determined and so the placement of sequencing primer is more flexible. As in other primer extension methods, excess PCR primers and dNTPs must be removed prior to the pyrosequencing reaction. Furthermore, 7 enzymes and two specialized reagents (APS and luciferin) are required in the homogeneous assay (4 enzymes are needed in the solid phase reaction format). These requirements make it almost impossible to keep the cost of genotyping lower than other approaches.

Multiplex Primer Extension Sorted on Genetic Arrays (Homogeneous Reaction With Separation/Capture on Solid Support and Fluorescence Detection)

To increase the SNP genotyping throughput, a number of groups have devised ways to perform the allelic discriminating primer extension reaction in multiplex in solution and separate the products by capturing them on solid support. One approach utilizes chimeric primer in the primer extension reaction with $3^{\prime}$ complementarity to the specific SNP loci and 5' complementarity to specific capture probes on solid support (Fan et al., 2000; Chen et al., 2000). The solid support can be color-coded microspheres or a silicon chip. The dye-labeled terminators provide the identity of the base incorporated whereas the specific capture probe sequence provides the identity of the SNP being assayed. Flow cytometry is used for sorting the microspheres and CCD imaging is used for microarray analysis. With this approach, one takes advantage of the more robust homogeneous reaction format in the allelic discrimination step and the capture probes on solid support to allow for multiplex reactions. Because the capture probes are generic, they can be designed in such a way that all of them will anneal optimally to their complementary sequences at the same temperature. Furthermore, the capture probes on microspheres and on the silicon chip can be made in high volume, therefore lowering the cost of the reagent. The only drawback of these approaches is that multiplex PCR and multiplex primer extension reaction are still not easy to optimize.

Ligation With Rolling Circle Amplification (Solid Phase Reaction With Fluorescence Detection)

Formation of a circular DNA molecule by ligation provides a means to perform SNP genotyping without PCR amplification. Two groups have shown that the circular DNA ligation product serves as a template for a rolling circle amplification (RCA) step that yields a product thousands of times the size of the original circle. If fluorescent nucleotides are used as the building blocks of the RCA reaction, the signal achieved is bright enough to allow one to detect single molecules. This approach has been used to determine the allele found on a single chromosome in FISH (fluorescent in situ hybridization) analysis and to genotype SNPs on solid support (Lizardi et al., 1998; Baner et al., 1998). The ability to obtain the genotype of SNPs directly from genomic DNA is a major advantage. This is perhaps the only method one can use to determine longrange haplotypes by FISH analysis. The high cost of the probes and the fact that only one level of specificity is involved make this approach one for special applications but not for general use.

\section{Homogeneous Ligation With FRET Detection}

When an allele specific oligonucleotide labeled with an acceptor dye is ligated to a oligonucleotide bearing a donor dye in the presence of the complementary target DNA, FRET is observed. Because PCR and ligation are different reactions, the assay can be done in a "closed tube" format by thermally isolating the two reactions (Chen et al., 1998). The PCR primers are designed to be long and anneal at a higher temperature while the ligation probes are designed to be short and therefore anneal only at a lower temperature. If the PCR reaction is allowed to proceed at high temperature, the ligation probes will not anneal and the 5'-probe will not be extended and taken out of the ligation reaction. After the PCR is largely completed, the thermal cycling conditions are changed and ligation is allowed to run at a lower temperature. FRET is monitored in real time and the genotypes can be determined quite easily by measuring the rate of emergence of fluorescence for the two dyes found on the allele-specific ligation probes. Because the ligation reaction is very specific, this reaction is probably the easiest of all "closed-tube" reactions to optimize. However, all 3 ligation probes are labeled with dyes and the start-up reagent cost is high.

Multiplex Ligation Reaction Sorted on Genetic Arrays (Homogeneous Reaction With Separation/Capture on Solid Support and Fluorescence Detection)

Like the microsphere/microarray based primer extension described above, the ligation assay can also be done in multiplex and captured/separated on solid support. Once again, chimeric probes are used where the 5 '-half of the sequence complements the capture probe and the 3 '-half of the sequence is allele-specific for a particular SNP. A reporter dye is used to label the common ligation probe such that it is captured along with the allele-specific ligation probe only if it is ligated to it in the presence of a DNA target with the correct allele (lannone, 2000). In this approach, only one of the three ligation probes are labeled with a dye. The two allele-specific ligation probes are labeled only with inexpensive nucleotide sequences. Furthermore, because ligation is very specific, multiplex ligation requires minimal optimization. The major disadvantage of this method is the need for 3 ligation probes compared to just one for the primer reaction. 
Invader Assay (Homogeneous Invasive Cleavage With FRET, FP, or Mass Spectrometry Detection)

The invader assay is based on the ability of a thermostable flap endonuclease to cleave a structure formed by the hybridization of two overlapping oligonucleotide probes to a target nucleic acid strand (Kaiser et al., 1999). By designing the flap probe with the allelic base at the overlapping site, the correct structure is formed only when the probes perfectly complement the DNA target. Upon cleavage, the flap released from the allele-specific probe (an arbitrary sequence unrelated to the SNP) serves as the "invader" probe in the secondary invader reaction. In the secondary reaction, a universal reporter probe is cleaved only when it forms the proper overlapping structure in the presence of the flap from the primary reaction. Taken together, the amplification is squared and the assay can work from genomic DNA without the need for target amplification (Kwiatkowski et al., 1999; Lyamichev et al., 2000; Hall et al., 2000). The flap design of the universal reporter probe is based on the detection method employed. For example, if mass spectrometry is the detection method to be used, flaps with varying number of nucleotides serve as the reporter signal (Griffin et al., 1999). If FRET is the detection method, a reporter dye is place on the flap while the quencher is placed on the annealed portion of the universal probe (Hall et al., 2000). For FP detection, the dye reporter is placed at the end of the flap (Hsu et al., 2001b)

The invader assay is an elegant SNP genotyping method and holds promise for directly assaying genomic DNA without PCR. However, the signal amplification approach suffers from the fact that only one level of specificity is utilized so that a significant fraction of SNPs in genomes with lots of repetitive sequences cannot be assayed by this method. Furthermore, although the primary probes are unlabeled, they must be exquisitely pure for them to work well in the system and this increases the cost of the starting reagents.

\section{Discussion and Conclusion}

SNP detection technologies have evolved from a laborintensive, painstaking endeavor involving numerous steps to a highly paralleled, automated process. Fancy (and expensive) instruments are used to analyze an everincreasing number of labels and reporters in reactions that produce large amounts of data. Bioinformatics is heavily relied upon for sample tracking, sequence comparisons, and data analysis. Indeed, the field has changed from one where molecular biologists tinkering with a few samples at a time to one where robots feeding thousands of DNA samples into gleaming instruments; from one where researchers painstakingly working through a series of reactions and reporting results manually to one where the results are analyzed and reported automatically by sophisticated computers at the end. With the human genome reference sequence almost complete and largescale sequencing an activity pursued by numerous groups, global SNP discovery is quite easily accomplished as long as funding is available. Targeted SNP discovery, though, is still at the stage of scanning relatively small segments of DNA one at a time. Either DNA sequencing becomes a lot cheaper and easier to do, or some new approach must be developed to allow for local SNP discovery on the hundred-kilobase to megabase scale.

Clever use of enzymatic and detection methods has produced a number of robust SNP genotyping methods in a variety of formats. However, despite recent advances in the field, none of the assays are ideally suited for all applications. Which genotyping assay to adopt therefore depends on the needs of the projects under consideration. In general, there are three scenarios to be considered. First, in a clinical diagnostic setting or when working with model organisms where a "canonical" set of markers are being tested on a stream of samples over an extended period of time, one can afford to invest in optimization of the assays. Here, the "closed-tube" assays that minimize contamination and sample mix-up are likely to dominate. Second, in a research study where new markers are constantly being identified and genotyped in hundreds of samples, assay development must be simple and the initial cost of assay development must be low. In this instance, primer extension reactions are the most logical choice. Third, in cases where thousands of markers must be used to type thousands of samples, multiplex assays are needed at very low operating cost. Here, some form of array-based multiplex genotyping method or a high-density reaction vessel capable of handling thousands of homogeneous assays will be needed. Unlike the first two scenarios, the large-scale genotyping studies are currently not feasible.

It is fair to say that with optimization, every SNP genotyping method can be made to work robustly and produce accurate results. Furthermore, a number of companies have put together systems for automated SNP genotyping. However, there are three areas that need special attention before an ideal genotyping assay, especially one that can handle large-scale genotpying projects, can be achieved. First, assay development has to be fast and inexpensive. Second, the cost of the assay (from instrumentation to reagents) must be affordable. Third, reactions must be done in a massively parallel fashion. Judging from the speed with which new genotyping assays are being invented, there is great hope that the ideal assay will be developed in the near future.

\section{Acknowledgement}

The text of the section on Technologies For Genotyping Known SNPs is an updated version of a previously published review article by the author (Kwok, P.-Y. 2001. Methods for Genotyping Single Nucleotide Polymorphisms. Annual Review of Genomics and Human Genetics 2: 235258) and is used with permission from the publisher of Annual Reviews.

\section{References}

Ahmadian, A., Gharizadeh, B., Gustafsson, A.C., Sterky, F., Nyren, P., Uhlen, M., and Lundeberg, J. 2000. Singlenucleotide polymorphism analysis by pyrosequencing. Anal. Biochem. 280: 103-110. 
Altshuler, D., Pollara, V.J., Cowles, C.R., Van Etten, W.J., Baldwin, J., Linton, L., and Lander, E.S. 2000. An SNP map of the human genome generated by reduced representation shotgun sequencing. Nature 407:513-516.

Babon, J.J., McKenzie, M., and Cotton, R.G. 2000. The use of resolvases T4 endonuclease VII and T7 endonuclease I in mutation detection. Methods Mol. Biol. 152: 187-199.

Baner, J., Nilsson, M., Mendel-Hartvig, M., and Landegren, U. 1998. Signal amplification of padlock probes by rolling circle replication. Nucleic Acids Res. 26: 5073-5078.

Barany, F. 1991. Genetic disease detection and DNA amplification using cloned thermostable ligase. Proc. Natl. Acad. Sci. USA. 88: 189-193.

Berlin, K. and Gut, I.G. 1999. Analysis of negatively 'charge tagged' DNA by matrix-assisted laser desorption/ ionization time-of-flight mass spectrometry. Rapid Commun Mass Spectrom. 13: 1739-1743.

Blazej, R.G., Paegel, B.M., and Mathies, R.A. 2003. Polymorphism ratio sequencing: a new approach for single nucleotide polymorphism discovery and genotyping. Genome Res. 13:287-93.

Botstein, D., White, R.L., Skolnick, M., and Davis, R.W. 1980. Construction of a genetic linkage map in man using restriction fragment length polymorphisms. Am. J. Hum. Genet. 32: 314-331.

Brow, M.A., Oldenburg, M.C., Lyamichev, V., Heisler, L.M., Lyamicheva, N., Hall, J.G., Eagan, N.J., Olive, D.M., Smith, L.M., Fors, L., and Dahlberg, J.E. 1996. Differentiation of bacterial 16S rRNA genes and intergenic regions and Mycobacterium tuberculosis katG genes by structure-specific endonuclease cleavage. J. Clin. Microbiol. 34: 3129-3137.

Buetow, K.H., Edmonson, M., MacDonald, R., Clifford, R., Yip, P., Kelley, J., Little, D.P., Strausberg, R., Koester, H., Cantor, C.R., and Braun, A. 2001. High-throughput development and characterization of a genomewide collection of gene-based single nucleotide polymorphism markers by chip-based matrix-assisted laser desorption/ ionization time-of-flight mass spectrometry. Proc. Natl. Acad. Sci. USA. 98: 581-584.

Cargill, M., Altshuler, D., Ireland, J., Sklar, P., Ardlie, K., Patil, N., Shaw, N., Lane, C.R., Lim, E.P., Kalyanaraman, N., Nemesh, J., Ziaugra, L., Friedland, L., Rolfe, A., Warrington, J., Lipshutz, R., Daley, G.Q., and Lander, E.S. 1999. Characterization of single-nucleotide polymorphisms in coding regions of human genes. Nat. Genet. 22: 231-238.

Chen, J., lannone, M.A., Li, M.S., Taylor, J.D., Rivers, P., Nelsen, A.J., Slentz-Kesler, K.A., Roses, A., and Weiner, M.P. 2000. A microsphere-based assay for multiplexed single nucleotide polymorphism analysis using single base chain extension. Genome Res. 10: 549-57.

Chen, X. and Kwok, P.-Y. 1997. Template-directed dyeterminator incorporation (TDI) assay: a homogeneous DNA diagnostic method based on fluorescence energy transfer. Nucleic Acids Res. 25: 347-353.

Chen,X., Zehnbauer, B., Gnirke, A., and Kwok, P.-Y. 1997. Fluorescence energy transfer detection as a homogeneous DNA diagnostic method. Proc. Natl. Acad. Sci. USA. 94: 10756-10761.
Chen, X., Livak, K., and Kwok, P.-Y. 1998. A homogeneous, ligase-mediated DNA diagnostic test. Genome Res. 8: 549-556.

Chen, X., Levine, L., and Kwok, P.-Y. 1999. Fluorescence polarization in homogeneous nucleic acid analysis. Genome Res. 9: 492-498.

Collins, F.S., Guyer, M.S., and Charkravarti, A. 1997. Variations on a theme: cataloging human DNA sequence variation. Science. 278:1580-1581.

Cooper, D.N., Smith, B.A., Cooke, H.J., Niemann, S., and Schmidtke, J. 1985. An estimate of unique DNA sequence heterozygosity in the human genome. Hum. Genet. 69: 201-205.

Cornell, B.A., Braach-Maksvytis, V.L., King, L.G., Osman, P.D., Raguse, B., Wieczorek, L., and Pace, R.J. 1997. A biosensor that uses ion-channel switches. Nature. 387: 580-583.

Cotton, R.G. 1999. Mutation detection by chemical cleavage. Genet. Anal. 14: 165-168.

Cotton, R.G., Rodrigues, N.R., and Campbell, R.D. 1988. Reactivity of cytosine and thymine in single-base-pair mismatches with hydroxylamine and osmium tetroxide and its application to the study of mutations. Proc. Nat. Acad. Sci. U.S.A. 85: 4397-4401.

Donis-Keller, H., Green, P., Helms, C., Cartinhour, S., Weiffenbach, B., Stephens, K., Keith, T.P., Bowden, D.W., Smith, D.R., Lander, E.S., et al. 1987. A genetic linkage map of the human genome. Cell 51: 319-337.

Dubiley, S., Kirillov, E., and Mirzabekov, A. 1999. Polymorphism analysis and gene detection by minisequencing on an array of gel-immobilized primers. Nucleic Acids Res. 27: e19.

Ekstrom, P.O., Borresen-Dale, A.L., Qvist, H., Giercksky, K.E., and Thilly, W.G. 1999. Detection of low-frequency mutations in exon 8 of the TP53 gene by constant denaturant capillary electrophoresis (CDCE). Biotechniques. 27: 128-134.

Faham, M. and Cox, D.R. 1995. A novel in vivo method to detect DNA sequence variation. Genome Res. 5: 474482.

Fan, J.B., Chen, X., Halushka, M.K., Berno, A., Huang, X., Ryder, T., Lipshutz, R.J., Lockhart, D.J., and Chakravarti, A. 2000. Parallel genotyping of human SNPs using generic high-density oligonucleotide tag arrays. Genome Res. 10: 853-860.

Fischer, S.G. and Lerman, L.S. 1983. DNA fragments differing by single base-pair substitutions are separated in denaturing gradient gels: correspondence with melting theory. Proc. Natl. Acad. Sci. USA. 80: 1579-1583.

Galas, D.J. and McCormack, S.J. 2002. Genomic Technologies: Present and Future. Caister Academic Press, Wymondham, UK.

Gao, Q. and Yeung, E.S. 2000. High-throughput detection of unknown mutations by using multiplexed capillary electrophoresis with poly(vinylpyrrolidone) solution. Anal. Chem. 72: 2499-2506.

Gelfi, C., Cremonesi, L., Ferrari, M., and Righetti, P.G. 1996. Temperature-programmed capillary electrophoresis for detection of DNA point mutations. BioTechniques 21:926932.

Germer, S. and Higuchi, R. 1999. Single-tube genotyping 
without oligonucleotide probes. Genome Res. 9: 72-78. Griffin, T.J., Hall, J.G., Prudent, J.R., and Smith, L.M. 1999. Direct genetic analysis by matrix-assisted laser desorption/ionization mass spectrometry. Proc. Natl. Acad. Sci. USA. 96: 6301-6306.

Hacia, J.G., Brody, L.C., Chee, M.S., Fodor, S.P.A., and Collins, F.S. 1996. Detection of heterozygous mutations in BRCA1 using high density oligonucleotide arrays and two-colour fluorescence analysis. Nature Genet. 14: 441447.

Hacia, J.G., Sun, B., Hunt, N., Edgemon, K., Mosbrook, D., Robbins, C., Fodor, S.P., Tagle, D.A., and Collins, F.S. 1998. Strategies for mutational analysis of the large multiexon ATM gene using high-density oligonucleotide arrays. Genome Res. 8: 1245-58.

Hall, J.G., Eis, P.S., Law, S.M., Reynaldo, L.P., Prudent, J.R., Marshall, D.J., Allawi, H.T., Mast, A.L., Dahlberg, J.E., Kwiatkowski, R.W., de Arruda, M., Neri, B.P., and Lyamichev, V.I. 2000. From the cover: sensitive detection of DNA polymorphisms by the serial invasive signal amplification reaction. Proc. Natl. Acad. Sci. USA. 97: 8272-8277.

Halushka, M.K., Fan, J.B., Bentley, K., Hsie, L., Shen, N., Weder, A., Cooper, R., Lipshutz, R., and Chakravarti, A. 1999. Patterns of single-nucleotide polymorphisms in candidate genes for blood-pressure homeostasis. Nat. Genet. 22:239-247.

Hanke, M. and Wink, M. 1994. Direct DNA sequencing of PCR-amplified vector inserts following enzymatic degradation of primer and dNTPs. BioTechniques 17: 858860.

Hansen, T.S., Petersen, N.E., litia, A., Blaabjerg, O., HyltoftPetersen, P., and Horder, M. 1995. Robust nonradioactive oligonucleotide ligation assay to detect a common point mutation in the CYP2D6 gene causing abnormal drug metabolism. Clin. Chem. 41: 413-418.

Hattori, M., Shibata, A., Yoshioka, K., and Sakaki, Y. 1993. Orphan peak analysis: a novel method for detection of point mutations using an automated fluorescence DNA sequencer. Genomics 15: 415-417.

Hawkins, G.A., and Hoffman, L.M. 1997. Base excision sequence scanning. Nature Biotech. 15: 803-804.

Hawkins, G.A., Hoffman, L.M. 1999. Rapid DNA mutation identification and fingerprinting using base excision sequence scanning. Electrophoresis. 20: 1171-1176.

Hayashi, K. 1991. PCR-SSCP: a simple and sensitive method for detection of mutations in the genomic DNA. PCR Methods Applic. 1: 34-38.

Hayashi, K. and Yandell, D.W. 1993. How sensitive is PCRSSCP? Hum. Mutation 2: 338-346.

Henco, K., Harders, J., Wiese, U., and Riesner, D. 1994. Temperature gradient gel electrophoresis (TGGE) for the detection of polymorphic DNA and RNA.Methods Mol. Biol. 31: 211-228.

Howell, W.M., Jobs, M., Gyllensten, U., and Brookes, A.J. 1999. Dynamic allele-specific hybridization. A new method for scoring single nucleotide polymorphisms. Nature Biotechnol. 17: 87-88.

Hsu, T.M., Chen, X., Duan, S., Miller, R., and Kwok, P.-Y. 2001a. A universal SNP genotyping assay with fluorescence polarization detection. BioTechniques, 31 :
560-570.

Hsu, T.M., Law, S.M., Duan, S., Neri, B.P., Kwok, P.-Y. 2001b. Genotyping single nucleotide polymorphisms by the Invader assay with dual-color fluorescence polarization detection. Clin. Chem. 47: 1373-1377.

Huber, C.G., Premstaller, A., Xiao, W., Oberacher, H., Bonn, G.K., and Oefner, P.J. 2001. Mutation detection by capillary denaturing high-performance liquid chromatography using monolithic columns. J. Biochem. Biophys. Methods.47: 5-19.

Hudson, T.J., Stein, L.D., Gerety, S.S., Ma, J., Castle, A.B., Silva, J., Slonim, D.K., Baptista, R., Kruglyak, L., Xu, S.H., et al. 1995. An STS-based map of the human genome. Science 270: 1945-1954.

lannone, M.A., Taylor, J.D., Chen, J., Li, M.S., Rivers, P., Slentz-Kesler, K.A., and Weiner, M.P. 2000. Multiplexed single nucleotide polymorphism genotyping by oligonucleotide ligation and flow cytometry. Cytometry. 39: 131-140.

Inazuka, M., Wenz, H.M., Sakabe, M., Tahira, T., and Hayashi, K. 1997. A streamlined mutation detection system: multicolor post-PCR fluorescence labeling and single-strand conformational polymorphism analysis by capillary electrophoresis. Genome Res. 7: 1094-1103.

International Human Genome Sequencing Consortium. 2001. Initial sequencing and analysis of the human genome. Nature 409: 860-921.

Irizarry, K., Kustanovich, V., Li, C., Brown, N., Nelson, S., Wong, W., and Lee, C.J. 2000. Genome-wide analysis of single-nucleotide polymorphisms in human expressed sequences. Nat. Genet. 26: 233-236.

Johnson, G.C. and Todd, J.A. 2000. Strategies in complex disease mapping. Curr. Opin. Genet. Dev. 10: 330-334.

Kaiser, M.W., Lyamicheva, N., Ma, W., Miller, C., Neri, B., Fors, L., and Lyamichev, V.I. 1999. A comparison of eubacterial and archaeal structure-specific 5'exonucleases. J. Biol Chem. 274: 21387-2194.

Keen, J., Lester, D., Inglehearn, C., Curtis, A., and Bhattacharya, S. 1991. Rapid detection of single base mismatches as heteroduplexes on Hydrolink gels. Trends Genet. 7: 5.

Kirschstein, S., Winter, S., Turner, D., and Lober, G. 1999. Detection of the DeltaF508 mutation in the CFTR gene by means of time-resolved fluorescence methods. Bioelectrochem Bioenerg. 48: 415-421.

Kostrikis, L.G., Tyagi, S., Mhlanga, M.M., Ho, D.D., and Kramer, F.R. 1998. Spectral genotyping of human alleles. Science 279: 1228-1229.

Krebs, S., Medugorac, I., Seichter, D., and Forster, M. 2003. RNaseCut: a MALDI mass spectrometry-based method for SNP discovery. Nucleic Acids Res. 31:e37.

Kwiatkowski, R.W., Lyamichev, V., de Arruda, M., and Neri, B. 1999. Clinical, genetic, and pharmacogenetic applications of the Invader assay. Mol. Diagn. 4:353-364.

Kwok, P.Y., Carlson, C., Yager, T.D., Ankener, W., and Nickerson, D.A. 1994. Comparative analysis of human DNA variations by fluorescence-based sequencing of PCR products. Genomics 23: 138-144.

Kwok, P.Y., Deng, Q., Zakeri, H., Taylor, S.L., and Nickerson, D.A. 1996. Increasing the information content of STS-based genome maps: identifying polymorphisms 
in mapped STSs. Genomics 31: 123-126.

Kwok, P.Y. and Chen, X. 1998. Detection of single nucleotide variations. Genet. Eng. (N Y). 20: 125-134.

Kwok, P.Y. 2000. High-throughput genotyping assay approaches. Pharmacogenomics. 1: 95-100.

Kwok P.Y. 2001. Reflections on a DNA mutation scanning tool. Nat. Biotechnol. 19: 18-19.

Laken, S.J., Jackson, P.E., Kinzler, K.W., Vogelstein, B., Strickland, P.T., Groopman, J.D., and Friesen, M.D. 1998. Genotyping by mass spectrometric analysis of short DNA fragments. Nature Biotechnol. 16: 1352-1356.

Latif, S., Bauer-Sardiña, I., Ranade, K., Livak, K., and Kwok, P.-Y. 2001. Fluorescence polarization in homogeneous nucleic acid analysis II: 5'-nuclease assay. Genome Res. 11: 436-440.

Li, J., Butler, J.M., Tan, Y., Lin, H., Royer, S., Ohler, L., Shaler, T.A., Hunter, J.M., Pollart, D.J., Monforte, J.A., Becker, C.H. 1999. Single nucleotide polymorphism determination using primer extension and time-of-flight mass spectrometry. Electrophoresis. 20: 1258-1265.

Lishanski, A., Ostrander, E.A., and Rine, J. 1994. Mutation detection by mismatch binding protein, MutS, in amplified DNA: application to the cystic fibrosis gene. Proc. Nat. Acad. Sci. U.S.A. 91: 2674-2678.

Litt, M. and Luty, J.A. 1989. A hypervariable microsatellite revealed by in vitro amplification of a dinucleotide repeat within the cardiac muscle actin gene. Am. J. Hum. Genet. 44: 397-401.

Livak, K.J. 1999. Allelic discrimination using fluorogenic probes and the 5' nuclease assay. Genet. Anal. 14: 143149.

Lizardi, P.M., Huang, X., Zhu, Z., Bray-Ward, P., Thomas, D.C., and Ward, D.C. 1998. Mutation detection and singlemolecule counting using isothermal rolling-circle amplification. Nature Genet. 19: 225-232.

Lyamichev, V.I., Kaiser, M.W., Lyamicheva, N.E., Vologodskii, A.V., Hall, J.G., Ma, W.P., Allawi, H.T., and Neri, B.P. 2000. Experimental and theoretical analysis of the invasive signal amplification reaction. Biochemistry. 39: 9523-9532.

Marth, G.T., Korf, I., Yandell, M.D., Yeh, R.T., Gu, Z., Zakeri, H., Stitziel, N.O., Hillier, L., Kwok. P,Y., and Gish, W.R. 1999. A general approach to single-nucleotide polymorphism discovery. Nat. Genet. 23: 452-456.

Masood, E. 1999. As consortium plans free SNP map of human genome. Nature 398: 545-546.

Mei, R., Galipeau, P.C., Prass, C., Berno, A., Ghandour, G., Patil, N., Wolff, R.K.., Chee, M.S., Reid, B.J., and Lockhart, D.J. 2000. Genome-wide detection of allelic imbalance using human SNPs and high-density DNA arrays. Genome Res. 10: 1126-1137.

Modrich, P. 1991. Mechanisms and biological effects of mismatch repair. Annu. Rev. Genet. 25: 229-253.

Myakishev, M.V., Khripin, Y., Hu, S., and Hamer, D.H. 2001. High-Throughput SNP genotyping by allele-specific PCR with universal energy-transfer-labeled primers. Genome Res. 11: 163-169.

Myers, R.M., Larin, Z., and Maniatis, T. 1985a. Detection of single base substitutions by ribonuclease cleavage at mismatches in RNA:DNA duplexes. Science 230: 12421246.
Myers, R.M., Lumelsky, N., Lerman, L.S., and Maniatis, T. 1985b. Detection of single base substitutions in total genomic DNA. Nature 313: 495-498.

Nickerson, D.A., Tobe, V.O., and Taylor, S.L. 1997. PolyPhred: automating the detection and genotyping of single nucleotide substitutions using fluorescence-based resequencing. Nucleic Acids Res. 25: 2745-2751.

Nordstrom, T., Nourizad, K., Ronaghi, M., and Nyren, P. 2000. Method enabling pyrosequencing on doublestranded DNA. Anal. Biochem. 282: 186-193.

Parker, B.O., and Marinus, M.G. 1992. Repair of DNA heteroduplexes containing small heterologous sequences in Escherichia coli. Proc. Nat. Acad. Sci. U.S.A. 89: 17301734.

Parker, L.T., Zakeri, H., Deng, Q., Spurgeon, S., Kwok, P.Y., and Nickerson, D.A. 1996. AmpliTaq DNA polymerase, FS dye-terminator sequencing: analysis of peak height patterns. BioTechniques 21: 694-699.

Pastinen, T., Kurg, A., Metspalu, A., Peltonen, L., and Syvanen, A.C. 1997. Minisequencing: a specific tool for DNA analysis and diagnostics on oligonucleotide arrays. Genome Res. 7: 606-614.

Pastinen, T., Raitio, M., Lindroos, K., Tainola, P., Peltonen, L., and Syvanen, A.C. 2000. A system for specific, highthroughput genotyping by allele-specific primer extension on microarrays. Genome Res. 10: 1031-1042.

Pease, A.C., Solas, D., Sullivan, E.J., Cronin, M.T., Holmes, C.P., and Fodor, S.P. 1994. Light-generated oligonucleotide arrays for rapid DNA sequence analysis. Proc. Nat. Acad. Sci. U.S.A. 91: 5022-5026.

Prince, J.A., Feuk, L., Howell, W.M., Jobs, M., Emahazion, T., Blennow, K., and Brookes, A.J. 2001. Robust and accurate single nucleotide polymorphism genotyping by dynamic allele-specific hybridization (dash): design criteria and assay validation. Genome Res. 11: 152-162. Risch, N.J. 2000. Searching for genetic determinants in the new millennium. Nature. 405: 847-856.

Rieder, M.J., Taylor, S.L., Tobe, V.O., and Nickerson, D.A. 1998. Automating the identification of DNA variations using quality-based fluorescence re-sequencing: analysis of the human mitochondrial genome. Nucleic Acids Res. 26: 967-973.

Ronaghi, M. 2001. Pyrosequencing Sheds Light on DNA Sequencing. Genome Res. 11: 3-11.

Ross, P., Hall, L., Smirnov, I., and Haff, L. 1998. High level multiplex genotyping by MALDI-TOF mass spectrometry. Nature Biotechnol. 16: 1347-1351.

Rossetti, S., Englisch, S., Bresin, E., Pignatti, P.F., and Turco, A.E. 1997. Detection of mutations in human genes by a new rapid method: cleavage fragment length polymorphism analysis (CFLPA). Mol. Cell. Probes 11: 155-160.

Saiki, R.K., Scharf, S., Faloona, F., Mullis, K.B., Horn, G.T., Erlich, H.A., and Arnheim, N. 1985. Enzymatic amplification of beta-globin genomic sequences and restriction site analysis for diagnosis of sickle cell anemia. Science 230: 1350-1354.

Sheffield, V.C., Cox, D.R., Lerman, L.S., and Myers, R.M. 1989. Attachment of a 40-base-pair $\mathrm{G}+\mathrm{C}$-rich sequence (GC-clamp) to genomic DNA fragments by the polymerase chain reaction results in improved detection 
of single-base changes. Proc. Natl. Acad. Sci. USA. 86: 232-236.

Sheffield, V.C., Beck, J.S., Kwitek, A.E., Sandstrom, D.W., and Stone, E.M. 1993. The sensitivity of single-strand conformation polymorphism analysis for the detection of single base substitutions. Genomics 16: 325-332.

Shumaker, J.M., Metspalu, A., and Caskey, C.T. 1996. Mutation detection by solid phase primer extension. Hum. Mutat. 7: 346-354.

Spiegelman, J.I., Mindrinos, M.N., and Oefner P.J. 2000. High-accuracy DNA sequence variation screening by DHPLC. Biotechniques 29: 1084-1092.

Svanvik, N., Stahlberg, A., Sehlstedt, U., Sjoback, R., and Kubista, M. 2000. Detection of PCR products in real time using light-up probes. Anal. Biochem. 287: 179-182.

Tabor, S. and Richardson, C.C. 1995. A single residue in DNA polymerases of the Escherichia coli DNA polymerase I family is critical for distinguishing between deoxy- and dideoxyribonucleotides. Proc. Nat. Acad. Sci. USA. 92: 6339-6343

Taillon-Miller, P., Gu, Z., Li, Q., Hillier, L., and Kwok, P.Y. 1998. Overlapping genomic sequences: a treasure trove of single-nucleotide polymorphisms. Genome Res. 8: 748754.

The International SNP Map Working Group. 2001. A map of human genome sequence variation containing 1.4 million SNPs. Nature. 409: 928-933.

Tian, H., Brody, L.C., Mao, D., and Landers, J.P. 2000. Effective capillary electrophoresis-based heteroduplex analysis through optimization of surface coating and polymer networks. Anal. Chem. 72: 5483-5492.

Todd, A.V., Fuery, C.J., Impey, H.L., Applegate, T.L., and Haughton, M.A. 2000. DzyNA-PCR: use of DNAzymes to detect and quantify nucleic acid sequences in a realtime fluorescent format. Clin. Chem. 46: 625-630.

Tonisson, N., Kurg, A., Kaasik, K., Lohmussaar, E., and Metspalu, A. 2000. Unravelling genetic data by arrayed primer extension. Clin. Chem. Lab. Med. 38: 165-170.

Tyagi, S., Bratu, D.P., and Kramer, F.R. 1998. Multicolor molecular beacons for allele discrimination. Nature Biotechnol. 16: 49-53.

Underhill, P.A., Jin, L., Lin, A.A., Mehdi, S.Q., Jenkins, T., Vollrath, D., Davis, R.W., Cavalli-Sforza, L.L., and Oefner,
P.J. 1997. Detection of numerous Y chromosome biallelic polymorphisms by denaturing high-performance liquid chromatography. Genome Res. 7: 996-1005.

Vaughan, P. and McCarthy, T.V. 1998. A novel process for mutation detection using uracil DNA-glycosylase. Nucleic Acids Res. 26: 810-815.

Venter, J.C., Adams, M.D., Myers, E.W., Li, P.W., Mural, R.J., Sutton, G.G., Smith, H.O., Yandell, M., et al. 2001. The sequence of the human genome. Science 291: 130451.

Wagner, R., Debbie, P., and Radman, M. 1995. Mutation detection using immobilized mismatch binding protein (MutS). Nucleic Acids Res. 23: 3944-3948.

Wang, D.G., Fan, J.B., Siao, C.J., Berno, A., Young, P., Sapolsky, R., Ghandour, G., Perkins, N., Winchester, E., Spencer, J., Kruglyak, L., Stein, L., Hsie, L., Topaloglou, T., Hubbell, E., Robinson, E., Mittmann, M., Morris, M.S., Shen, N., Kilburn, D., Rioux, J., Nusbaum, C., Rozen, S., Hudson, T.J., Lander, E.S., et al. 1998. Large-scale identification, mapping, and genotyping of singlenucleotide polymorphisms in the human genome. Science 280: 1077-1082.

Wang, J., Cai, X., Rivas, G., Shiraishi, H., and Dontha, N. 1997. Nucleic-acid immobilization, recognition and detection at chronopotentiometric DNA chips. Biosens Bioelectron. 12: 587-599.

Weber, J.L. and May, P.E. 1989. Abundant class of human DNA polymorphisms which can be typed using the polymerase chain reaction. Am. J. Hum. Genet. 44: 388396.

Youil, R., Kemper, B.W., and Cotton, R.G.H. 1995. Screening for mutations by enzyme mismatch cleavage with T4 endonuclease VII. Proc. Nat. Acad. Sci. USA. 92: 87-91.

Youil, R., Kemper, B., and Cotton, R.G. 1996. Detection of 81 of 81 known mouse beta-globin promoter mutations with T4 endonuclease VII-the EMC method. Genomics 32: 431-435.

Zakeri, H., Amparo, G., Chen, S.M., Spurgeon, S., and Kwok, P.Y. 1998. Peak height pattern in dichlororhodamine and energy transfer dye terminator sequencing. Biotechniques 25: 406-414. 


\section{Further Reading}

Caister Academic Press is a leading academic publisher of advanced texts in microbiology, molecular biology and medical research. Full details of all our publications at caister.com

- MALDI-TOF Mass Spectrometry in Microbiology Edited by: M Kostrzewa, S Schubert (2016) www.caister.com/malditof

- Aspergillus and Penicillium in the Post-genomic Era Edited by: RP Vries, IB Gelber, MR Andersen (2016) www.caister.com/aspergillus2

- The Bacteriocins: Current Knowledge and Future Prospects Edited by: RL Dorit, SM Roy, MA Riley (2016)

www.caister.com/bacteriocins

- Omics in Plant Disease Resistance Edited by: V Bhadauria (2016) www.caister.com/opd

- Acidophiles: Life in Extremely Acidic Environments Edited by: R Quatrini, DB Johnson (2016) www.caister.com/acidophiles

- Climate Change and Microbial Ecology: Current Research and Future Trend

Edited by: J Marxsen (2016)

www.caister.com/climate

- Biofilms in Bioremediation: Current Research and Emerging Technologies

Edited by: G Lear (2016)

www.caister.com/biorem

- Microalgae: Current Research and Applications Edited by: MN Tsaloglou (2016) www.caister.com/microalgae

- Gas Plasma Sterilization in Microbiology: Theory, Applications, Pitfalls and New Perspectives Edited by: H Shintani, A Sakudo (2016) www.caister.com/gasplasma

- Virus Evolution: Current Research and Future Directions Edited by: SC Weaver, M Denison, M Roossinck, et al. (2016) www.caister.com/virusevol

- Arboviruses: Molecular Biology, Evolution and Control Edited by: N Vasilakis, DJ Gubler (2016) www.caister.com/arbo

- Shigella: Molecular and Cellular Biology Edited by: WD Picking, WL Picking (2016) www.caister.com/shigella

-Aquatic Biofilms: Ecology, Water Quality and Wastewater Treatment

Edited by: AM Romaní, H Guasch, MD Balaguer (2016)

www.caister.com/aquaticbiofilms

- Alphaviruses: Current Biology

Edited by: S Mahalingam, L Herrero, B Herring (2016)

www.caister.com/alpha

- Thermophilic Microorganisms

Edited by: F Li (2015)

www.caister.com/thermophile
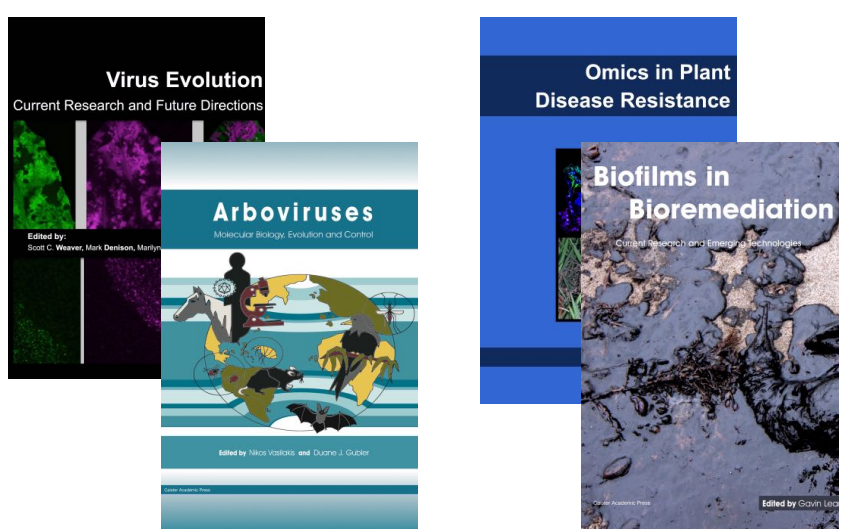
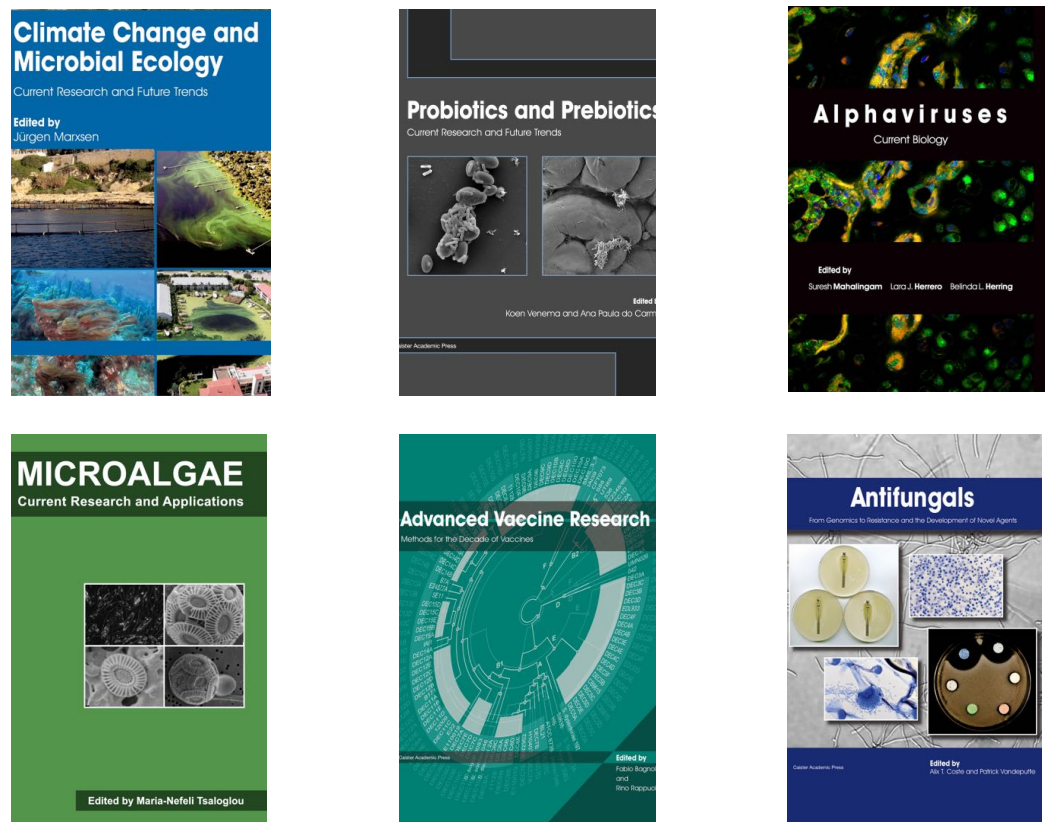

- Flow Cytometry in Microbiology: Technology and Applications Edited by: MG Wilkinson (2015) www.caister.com/flow

- Probiotics and Prebiotics: Current Research and Future Trends Edited by: K Venema, AP Carmo (2015) www.caister.com/probiotics

- Epigenetics: Current Research and Emerging Trends Edited by: BP Chadwick (2015) www.caister.com/epigenetics2015

- Corynebacterium glutamicum: From Systems Biology to Biotechnological Applications

Edited by: A Burkovski (2015)

www.caister.com/cory2

- Advanced Vaccine Research Methods for the Decade of Vaccines

Edited by: F Bagnoli, R Rappuoli (2015)

www.caister.com/vaccines

- Antifungals: From Genomics to Resistance and the Development of Novel Agents

Edited by: AT Coste, P Vandeputte (2015)

www.caister.com/antifungals

- Bacteria-Plant Interactions: Advanced Research and Future Trends Edited by: J Murillo, BA Vinatzer, RW Jackson, et al. (2015) www.caister.com/bacteria-plant

\section{- Aeromonas}

Edited by: J Graf (2015)

www.caister.com/aeromonas

- Antibiotics: Current Innovations and Future Trends

Edited by: S Sánchez, AL Demain (2015)

www.caister.com/antibiotics

- Leishmania: Current Biology and Contro Edited by: S Adak, R Datta (2015) www.caister.com/leish2

- Acanthamoeba: Biology and Pathogenesis (2nd edition) Author: NA Khan (2015)

www.caister.com/acanthamoeba2

- Microarrays: Current Technology, Innovations and Applications Edited by: Z He (2014)

www.caister.com/microarrays2

- Metagenomics of the Microbial Nitrogen Cycle: Theory, Methods and Applications

Edited by: D Marco (2014)

www.caister.com/n2 